\title{
AARE_ACTIVATION Script Version 2.0 User Guide
}

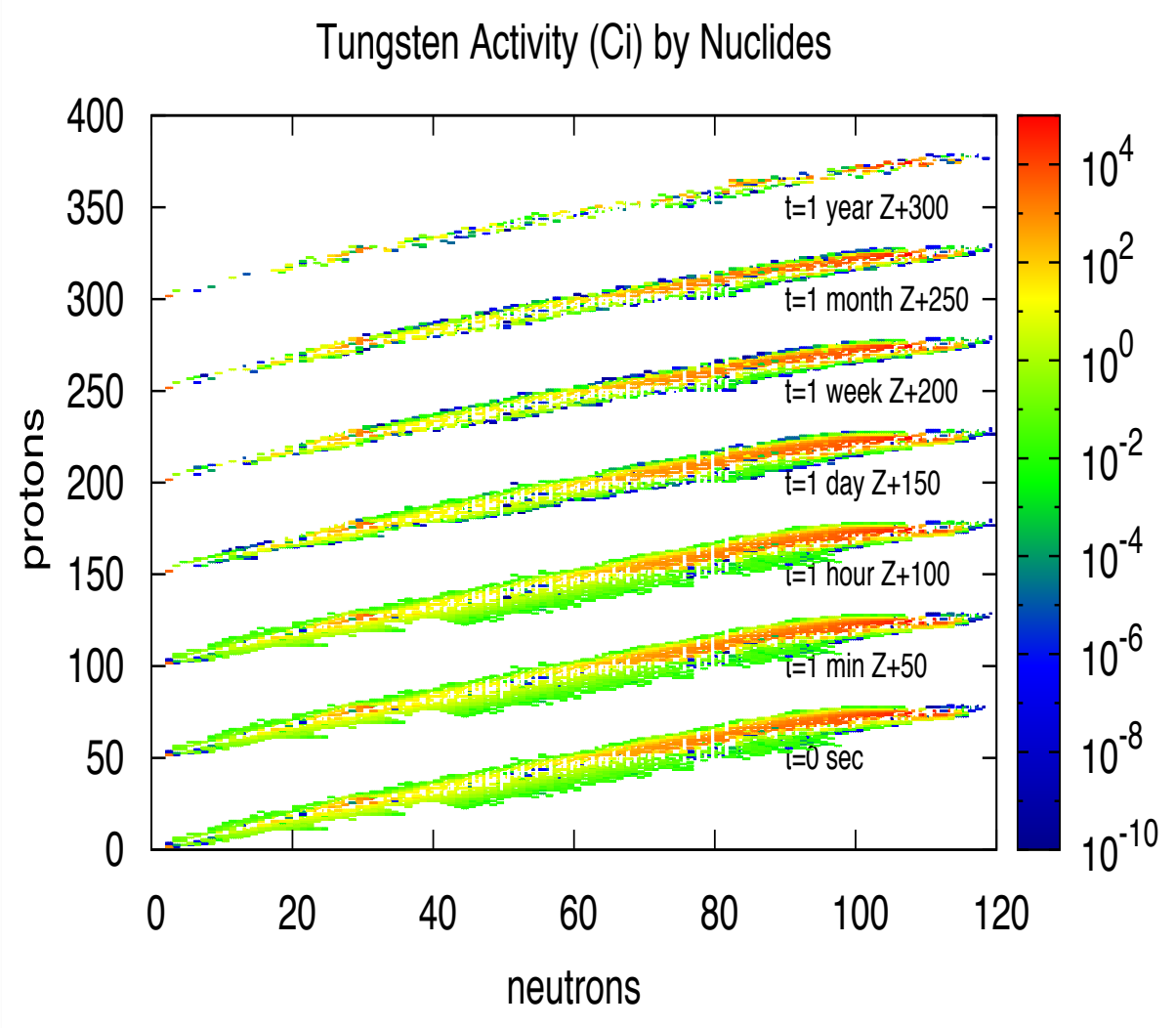

Approved for public release

OAK RIDGE NATIONAL LABORATORY

MANAGED BY UT-BATTELLE FOR THE US DEPARTMENT OF ENERGY
Franz. X Gallmeier Michael Wohlmuther

July 2018 


\section{DOCUMENT AVAILABILITY}

Reports produced after January 1, 1996, are generally available free via US Department of Energy (DOE) SciTech Connect.

Website http://www.osti.gov/scitech/

Reports produced before January 1, 1996, may be purchased by members of the public from the following source:

National Technical Information Service

5285 Port Royal Road

Springfield, VA 22161

Telephone 703-605-6000 (1-800-553-6847)

TDD 703-487-4639

Fax 703-605-6900

E-mail info@ntis.gov

Website http://classic.ntis.gov/

Reports are available to DOE employees, DOE contractors, Energy Technology Data Exchange representatives, and International Nuclear Information System representatives from the following source:

Office of Scientific and Technical Information

PO Box 62

Oak Ridge, TN 37831

Telephone 865-576-8401

Fax 865-576-5728

E-mail reports@osti.gov

Website http://www.osti.gov/contact.html

This report was prepared as an account of work sponsored by an agency of the United States Government. Neither the United States Government nor any agency thereof, nor any of their employees, makes any warranty, express or implied, or assumes any legal liability or responsibility for the accuracy, completeness, or usefulness of any information, apparatus, product, or process disclosed, or represents that its use would not infringe privately owned rights. Reference herein to any specific commercial product, process, or service by trade name, trademark, manufacturer, or otherwise, does not necessarily constitute or imply its endorsement, recommendation, or favoring by the United States Government or any agency thereof. The views and opinions of authors expressed herein do not necessarily state or reflect those of the United States Government or any agency thereof. 
ORNL/TM-2018/1036

Neutron Sciences Directorate

Neutron Technologies Division

\section{AARE ACTIVATION SCRIPT VERSION 2.0 USER GUIDE}

Franz X. Gallmeier

Michael Wohlmuther

Date Published- July, 2018

Prepared by the OAK RIDGE NATIONAL LABORATORY

Oak Ridge, Tennessee 37831

managed by

UT-Battelle, LLC

for the

U.S. DEPARTMENT OF ENERGY

under contract DE-AC05-00OR22725 
Table of Contents

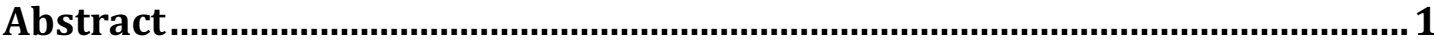

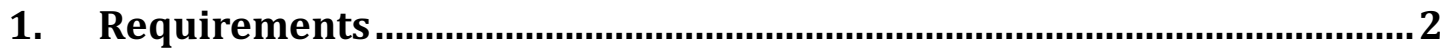

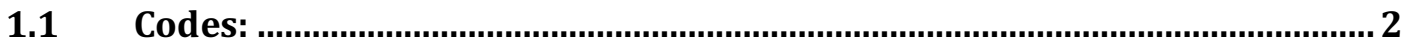

1.2 Files:

1.3 Directions for MCNPX run:....................................................................... 2

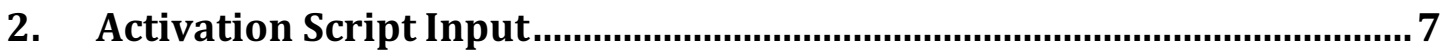

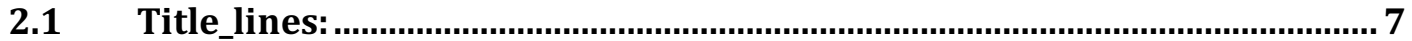

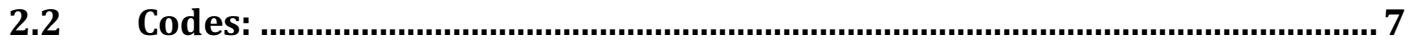

$2.3 \quad$ Files:

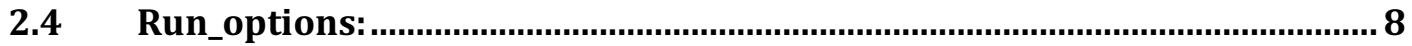

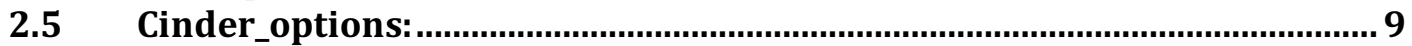

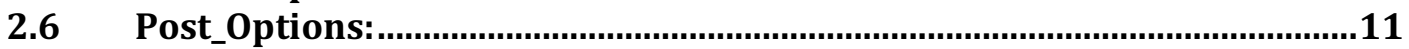

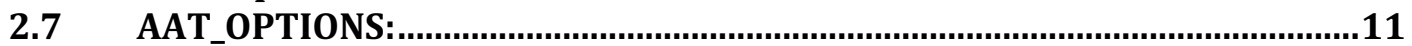

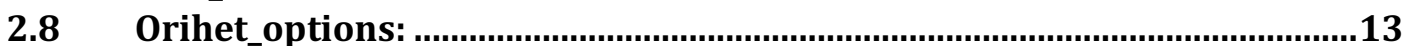

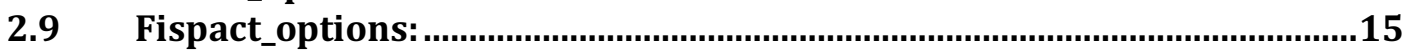

2.10 Normalization: ..............................................................................................17

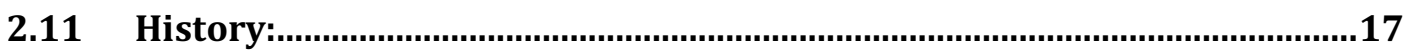

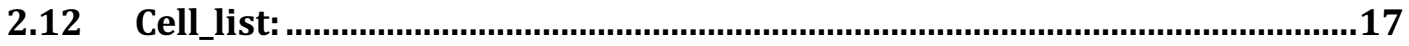

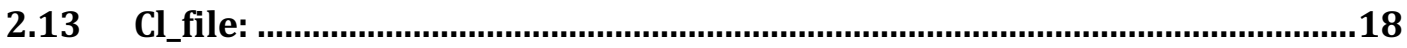

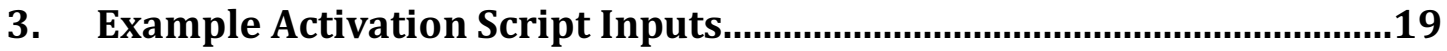

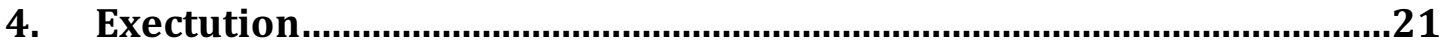

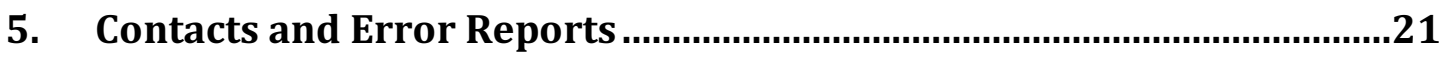

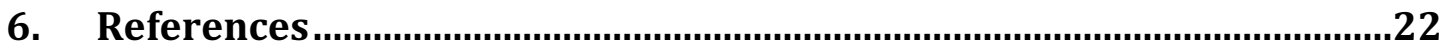

Appendix 1. CINDER2008 Multi-group energy structures ..........................23

Appendix 2: FISPACT Multi-group energy structures .....................................26 


\begin{abstract}
AARE_ACTIVATION prepares the input files for various activation codes from MCNPX $^{1-2}$ or MCNP6 $^{3}$ output and runs them. Three activation codes are presently supported: CINDER2008 ${ }^{4}$, SP-FISPACT ${ }^{5-6}$ from the EASY-2010 code package, and ORIHET3 ${ }^{7}$. The script assumes that the requested activation code is installed on the computer with all ancillary files and data libraries such that it can be executed through the settings of the PATH environment variable or by defining the absolute path of the executable name in the input of AARE ACTIVATION.

AARE_ACTIVATION is distributed in the AARE code package, which also includes CINDER2008. If the user wants to run the ORIHET3 and SP-FISPACT codes, the user will need to inquire after the respective codes as indicated in the references.

In case problems are encountered running AARE_ACTIVATION, the authors would be pleased receiving a report of the problems, including the inputs and names of code versions that were applied.
\end{abstract}




\section{REQUIREMENTS}

\subsection{CODES:}

- AARE_ACTIVATION as distributed with the AARE 1.0 package

- HTAPE3X code from MCNPX package version 2.7.0 (MCNPX not needed per se but its outputs)

- CINDER2008 as distributed with the AARE 1.0 package

As an alternative to CINDER2008:

- $\quad$ SP-FISPACT code from the EASY Code package version 2010

- ORIHET3 code version 1.12

\subsection{FILES:}

- Bigza: Listing of natural abundance by isotope provided with the Activation Script

- MCNPX or MCNP6 output file

- A histp file produced by MCNPX or tallies of spallation induced production rates tallied by the RNUCS card (requires patched MCNPX or MCNP6 ${ }^{*}$ ) or spallation products are disregarded (see AARE_ACTIVATION input: run_options)

- AARE_ACTIVATION input file

\subsection{DIRECTIONS FOR MCNPX RUN:}

AARE_ACTIVATION reads most of the problem information, like cell properties, material compositions, and neutron fluxes, from the MCNPX output file. Proton and deuteron fluxes, and the activation resulting from them, is supported when FISPACT from the EASY2010 package is used as the transmutation engine. MCNP6 output is also supported, but since the HISTP formalism is broken (as of MCNP6.2), the use of MCNP6 in conjunction with AARE_ACTIVATION is limited to problems not using physics models. A way out of this dilemma is patching MCNP6 with the RNUCS tally (patches included in this package). The script hunts for key strings of tables and tallies in the MCNPX or MCNP6 output. The cell information is read from print table 60, the material information from the reported input cards, the neutron fluxes, including the cell volumes, from tally f4. The MCNPX input must be instrumented accordingly. To perform a full activation calculation within the energy range from the MCNPX physics model region down to the table data region, two sources of residual nuclide production must be considered:

In the physics model region isotope production and destruction rates are reported on an event file called histp. This option is enabled with the HISTP card - see later in this chapter. To take into account the activation by neutrons with energies in the table region an $F 4: n$ tally with a multigroup energy structure must be specified. Tally multipliers (EM4 or EMO

\footnotetext{
${ }^{*}$ Patch files are included with the CINDER2008 package that allows updating MCNPX versions 2.6.0 and 2.7.0 and MCNP 6.1 with the RNUCS tally.
} 
cards) are not allowed, and a FQ4 card for the $F 4: n$ tally for rearranging the output format is not permitted.

WARNING: AARE_ACTIVATION tests for use of the EM0, EM4, CM4 or TM4 cards with the $F 4: n$ tally and stops execution if these are present. It does not test for the presence of a FQ4 card!

CAVEAT: At present MCNPX and MCNP6 problems involving repeated structures and lattices are not supported. No check is made if they are present.

Proton and/or deuteron fluxes, if used, are to be tallied by $F 14: h$, and $F 24: d$, respectively. As for neutron flux tallies, the use of $E M, F Q, C M$, or $T M$ multipliers in combination with $F 14$ or F24 are not permitted.

Although AARE_ACTIVATION works with any multigroup structure and re-bins the fluxes into the energy structure of the requested libraries, it uses user provided typical energy structures to achieve a best match.

WARNING: Systematic errors may materialize by a mismatch of the energy structure between activation cross sections being applied by the transmutation code of choice and MCNPX fluxes if the requested energy function does not fit the flux conditions.

These systematic errors can be avoided by tallying the fluxes in the multigroup energy structure of the specific library requested for the analysis. Those are different for each of the supported transmutation codes and their library options. To use the ORIHET3 or FISPACT code, please consult also the section AARE_ACTIVATION Input, in particular the description of orihet_options and fispact_options, before choosing a particular energy group structure.

- CINDER2008 provides three libraries to choose from: a 66-group library for fissile systems, a 172-group library for fusion systems (identical with the EAF 172-group structure, see below), and a 321-group library (similar to the EAF 315 Tripoli group structure). The multigroup cross sections are collapsed from continuous energy evaluated data by using fission, fusion, and flat energy spectra, respectively. The user should determine which library would best fit his or her application. It is recommended, but not mandatory, to use that library group structure for the neutron flux tally F4: $n$.

- $\quad$ FISPACT comes with neutron multigroup libraries with 69, 100, 172, 175, 211, 315 , and 351 energy groups. It is recommended to use the same multi-group energy structure in the MCNPX calculations as used by FISPACT. For proton and deuteron driven activation, libraries with 211 energy groups are provided. The number of energy groups is an input parameter in the AARE_ACTIVATION input (see Activation Script Input: fispact_options block).

- ORIHET3 does not use neutron fluxes and activation cross sections, but just reads isotope production rates. Therefore AARE_ACTIVATIN folds the neutron fluxes 
from the F4: $n$ tally with activation cross sections to provide isotope production rates to ORIHET3. AARE_ACTIVATION offers two ways to do this:

O Using continuous energy activation cross sections from the FENDLA $/ 1.1^{8}$, the EAF $2003^{9}$, or the EAF-2005 ${ }^{10}$ libraries. The selected library is collapsed to the MCNPX group structure by the GROUPIE ${ }^{11}$ code allowing the user full freedom of the choice of energy group structures for the neutron fluxes. These libraries must be provided in a linearized format for the use with GROUPIE.

WARNING: The FENDLA/1.1 library does not include information for actinides.

- Multigroup cross sections from the EASY-2010 12 package can be used with the same recommendations as given for FISPACT. The use of proton and deuteron activation cross sections is not supported by AARE ACTIVATION for use with ORIHET3.

Isotope production and destruction rates from interactions described by the MCNPX physics

models are reported by MCNPX on an event file (histp) using the HISTP card. The HTAPE3X code evaluates the histp file(s) for cell-based isotope production and destruction rates. AARE ACTIVATION prepares the necessary HTAPE3X input files, executes three HTAPE3X runs (for isotope production rates, for gas production rates, and for isotope destruction rates), and reads the necessary information from the HTAPE3X output.

At ORNL a tally extension was developed that allows tallying the cell-based isotope production and destruction rates directly in $\mathrm{MCNPX}^{14}$ or MCNP6. This capability is activated by the RNUCS card (see footnote page 2). This avoids having to post-process large event files with HTAPE3X. The standard MCNPX (MCNP6) code must be patched using the provided patch files to allow for the use of the RNUCS card. Patches are provided for MCNPX 2.6.0, MCNPX 2.7.0, and MCNP 6.1.

The following cards must be present in the MCNPX input to obtain the physics model isotope production and destruction rates:

- HISTP card for all cells of interest (or all cells)

or

- $\quad R N U C S$ card (requires a patched MCNPX version) followed by the keyword cinder and the keyword normal or impure (spallation isotope production and destruction tally) and a list of cells of interest (or all cells). For the setting impure, MCNPX performs a spallation event analysis for each of the isotopes of the material composition in the respective cell to improve the statistics of the radionuclide outcome from material components with low abundance [14].

Because the implementation of the neutron activation isotope production and destruction rates is based on neutron activation cross section libraries with an upper energy limit of 25 $\mathrm{MeV}$ for the CINDER2008 66 and 321 group libraries, or $20 \mathrm{MeV}$ for the CINDER2008 fusion library or the FENDL and EAF based cross section libraries, the neutron transport in MCNPX must reflect this condition. EASY-2010 also provides 211 and 351 group 
activation cross sections with upper energies of $60 \mathrm{MeV}$. Therefore, the use of neutron transport cross sections in the MCNPX code has to be set to 20,25 , or $60 \mathrm{MeV}$, respectively, corresponding to the cross section set to be used in the activation analyses, by providing the card

\section{PHYS:n EMAX EAN IUNR DBN 20.0/25.0/60.0}

Normally physics models must be used for all hadron and meson physics, which does not allow the use of existing proton cross section libraries. To use physics models for proton transport at all energies use the card

\section{PHYS:h EMAX EAN 0.0 j ISTRG j RECL}

When using the EASY-2010 proton activation cross section ${ }^{13}$, which extends to the energy of $60 \mathrm{MeV}$, for proton induced activation analyses in combination with the FISPACT code, the user can consider using the tabulated proton cross sections to $60 \mathrm{MeV}$, and physics models above $60 \mathrm{MeV}$. The proton physics card for this case take the form:

\section{PHYS:h EMAX EAN 60.0 j ISTRG $j$ RECL}

In cases that use isotope production from the physics models in combination with proton activation cross sections to $60 \mathrm{MeV}$, the user must provide to MCNPX tabulated proton cross sections for all material nuclides of the problem, in order to prevent possible double counting of production channels. In problems that use the deuteron activation cross sections as provided by EASY-2010, the use of physics model induced activation is strongly discouraged. This would lead to double counting the reaction channels induced by deuterons up to $60 \mathrm{MeV}$ energy because MCNPX does not allow for tabulated deuteron cross sections to be used (see the mix-and-match discussion below).

AARE_ACTIVATION does not check for the existence of PHYS cards and their settings.

WARNING: Improper settings of the PHYS cards may cause loss of coverage of the isotope production and destruction rates below 150-200 MeV (the upper energy of some neutron and proton cross section data libraries).

Only isotope production from physics model events are written to the histp file. The CINDER2008 66 and 321 group libraries presently have activation cross section data only for neutrons up to $25 \mathrm{MeV}$, the CINDER2008 172 group library and the EAF and FENDL based activation cross sections are defined up to $20 \mathrm{MeV}$. Setting TABL $\left(5^{\text {th }}\right.$ entry on the MCNPX PHYS: $n$ card) to the upper table energy causes all neutrons interactions above the upper table energy to be recorded in histp. Setting $T A B L$ ( $3^{\text {rd }}$ entry) on the proton physics card to $0 \mathrm{MeV}$ ensures all proton interactions are recorded on histp. The combined result is that activation for all energies up to $E M A X$ is covered for both particles, by either physics model event data in histp or cross section data in the respective libraries.

There are transport accuracy implications. Higher fidelity transport calculations generally result from using the MCNPX mix-and-match default, where evaluated cross section data is used where available for both neutrons and protons, and the physics models are used only where the table data does not exist. Using mix-and-match will not work for the 
activation calculation because the histp file will not contain any of the table processed interaction information and only has the cross sections to do neutron activation in the energy range of the activation cross section library using the tallied fluxes. A user may run the flux and histp calculations separately, using default mix-and-match for a better neutron flux calculation and the required physics options for the histp calculation. Note that the word HISTP must still exist in the flux calculation output for AARE_ACTIVATION to work. This can be accomplished by editing the MCNPX output adding a HISTP data card in the input listing.

WARNING: When using a neutron physics TABL value of $25 \mathrm{MeV}$ with MCNPX neutron cross section tables that end at $20 \mathrm{MeV}$, note that the $20 \mathrm{MeV}$ cross section table value is used for transport between 20 and $25 \mathrm{MeV}$, rather than the physics model. The user may accept this treatment, run the flux and histp calculations separately, or lower $T A B L$ to

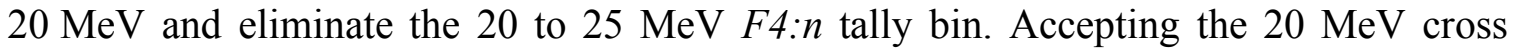
section projection to $25 \mathrm{MeV}$ is often reasonable. Running the histp and flux calculations separately as described afore allows a more accurate neutron flux calculation to $25 \mathrm{MeV}$ while the table data below $25 \mathrm{MeV}$ is not particularly relevant to the histp calculation. If the neutron physics $T A B L$ value is lowered to $20 \mathrm{MeV}$, the flux tally should also stop at 20 $\mathrm{MeV}$. This will ensure that the neutron flux in the 20 to $25 \mathrm{MeV}$ group is zero as input to CINDER2008 preventing double counting of neutron activation in this range, which will result if in the energy range, both histp events are recorded and a nonzero neutron flux is input.

WARNING: The user may want to carefully screen the MCNPX output for warning messages "use models for the following missing data tables". If the MCNPX code is not able to find a data table for a requested cross section ID in the material definition, it automatically uses physics models. This applies both to neutron and proton cross section tables. Missing neutron tables, in most cases, can be resolved using IDs with existing tables. Missing proton tables indicate that the phys: $h$ card's third entry is not set to zero. 


\section{AARE_ACTIVATION INPUT}

AARE_ACTIVATION input contains 10 blocks of information separated from each other by a blank line, and starting with the following key words:

- codes

- title_lines

- files

- run_options

- cinder_options

- post_options

- aat_options

- fispact_options

- orihet_options

- normalization

- history

- cell_list

- $c l$ file

Any line starting with the \# character is interpreted as comment, as well as any information in a line following the \# character.

The keywords and their options are case insensitive. All blocks of input can be given in any order except for the cell_list block, which requires the title_lines, files, cinder_options (optionally fispact_options or orihet_options), normalization, and history blocks of input already provided. The codes and run_options blocks are optional. Providing a cell_list block triggers a full activation calculation. Any number of cell_list blocks can be provided, separated by any number of other blocks or by no other blocks. Each calculation uses the latest block information provided. The following describes the input blocks in detail:

\subsection{TITLE_LINES:}

Any number of lines following the keyword title_lines are output as comments by AARE_ACTIVATION. Up to 20 such lines are processed by CINDER2008. Only the first title line is used by ORIHET3. Using FISPACT, the title lines appear as header of the main input file.

\subsection{CODES:}

This card allows the user to provide executable names for the codes cinder2008, tabcode, orihet, groupie, fispact, and htape $3 x$, and is optional. The default executable names "cinder2008", "orihet3", "groupie", "spfisp03", and "htape3x" are used if this block is not provided or the default settings are not changed. 
The following keywords are allowed:

\begin{tabular}{|l|l|l|}
\hline Keyword & Description & Defaults \\
\hline cinder & followed by cinder executable name & "cinder2008" \\
\hline post & followed by post executable name & "post2008" \\
\hline orihet & followed by orihet3 executable name & "orihet3" \\
\hline groupie & followed by groupie executable name & "groupie" \\
\hline fispact & followed by fispact executable name & "spfisp10" \\
\hline htape3x & followed by htape3x executable name & "htape3x" \\
\hline
\end{tabular}

The user can provide an executable name with the full path name to override operating system specific settings via a PATH environment variable.

\subsection{FILES:}

This block provides file names the script uses to read material, flux and isotope production/destruction information. It allows four keywords:

\begin{tabular}{|l|l|l|}
\hline Keyword & Description & Defaults \\
\hline mcnpx_outp & $\begin{array}{l}\text { followed by the MCNPX } \\
\text { output file name }\end{array}$ & "outp" \\
\hline mcnpx_cont & $\begin{array}{l}\text { followed by the output of a } \\
\text { MCNPX continue run }\end{array}$ & none \\
\hline mcnpx_histp & $\begin{array}{l}\text { followed by the MCNPX } \\
\text { histp file name }\end{array}$ & histp \\
\hline bigza_file & $\begin{array}{l}\text { followed by the bigza file } \\
\text { name including path }\end{array}$ & $\begin{array}{l}\text { dependent on operating } \\
\text { system, either } \\
\text { "//usr/local/cinder/data/bigza" } \\
\text { or "c:laareldatalbigza" }\end{array}$ \\
\hline
\end{tabular}

In the case the user provides a mcnpx_cont file name, AARE_ACTIVATION merges the MCNPX output file and the MCNPX continue file to a master MCNPX output file to be used for extracting the relevant transport run information. If these files are not in the directory where the script is run, the keywords should provide the full pathname.

\subsection{RUN_OPTIONS:}

This block provides information that influences the execution of the script:

\begin{tabular}{|l|l|l|}
\hline Keyword & Description & Defaults \\
\hline dname & $\begin{array}{l}\text { a string to be used to form a directory } \\
\text { name for saving the activation code } \\
\text { input and output file calling this option } \\
\text { also resets the dcounter to 1 }\end{array}$ & "run" \\
\hline dcounter & $\begin{array}{l}\text { an integer value to be appended to } \\
\text { dname }\end{array}$ & 1 \\
\hline
\end{tabular}




\begin{tabular}{|l|l|l|}
\hline splprods & spallation product switch & 1 \\
\hline tabular & neutron activation switch & 1 \\
\hline verbose & $\begin{array}{l}\text { switch to save intermediate execution } \\
\text { files to the respective problem directory } \\
(0=\text { off, } 1=\text { on })\end{array}$ & 0 \\
\hline
\end{tabular}

The variables splprods and tabular are switches that control the processing of spallation products or low-energy $(\mathrm{E}<20 \mathrm{MeV})$ neutron activation products, respectively $(0=\mathrm{off}$, else $=$ on). Either splprods or tabular, or both, must be set to 1 . Problems with no isotope production terms (decay only) are prepared by defining a zero power level through the history block. The variables dname and dcounter are not reset to the default values at the call of the run_options block, but are set to the default values only at the start of the script.

\subsection{CINDER_OPTIONS:}

This block provides parameter settings to be used by the CINDER2008 code. Providing the cinder_options without any entries resets all values to the defaults. Providing the block name also triggers the activation calculations to be performed using the CINDER2008 code unless a orihet_options or fispact_options block appears before the cell_list block is provided. The following parameters are directly passed on to CINDER2008. A more detailed description of the following is given in the CINDER2008 manual:

\begin{tabular}{|l|l|l|}
\hline Keyword & Description & Defaults \\
\hline tst & $\begin{array}{l}\text { chain cut off with regard to nuclide } \\
\text { density fraction of previous time step }\end{array}$ & 0.0 \\
\hline shain cut off with regard to initial nuclide \\
$\begin{array}{l}\text { density fraction or activity of initial time } \\
\text { step }\end{array}$ & 0.0 \\
\hline epsm & $\begin{array}{l}\text { exp(-arg)=1 for arg<epsm } \\
1 \text {-exp(-arg) }=\text { arg for arg<epsm }\end{array}$ & 0.0 \\
\hline epsn & $\begin{array}{l}\text { The reciprocal of a power of 10 having } \\
\text { exponent exceeding not the significant } \\
\text { digits of the computer stored word }\end{array}$ & 0.0 \\
\hline exponmax & maximum exponent guaranteed & 0.0 \\
\hline kchn & request of chains file (1=on, 0=off) & 0 \\
\hline klib & request of libchek file1=on, $0=$ off) & 0 \\
\hline nfe & $\begin{array}{l}\text { fission product flag (0=none, 1=thermal, } \\
\text { 2=fast, 3=high-energy) }\end{array}$ & 3 \\
\hline nosame & chain loops (0=disallowed, 1=allowed) & 0 \\
\hline fine & $\begin{array}{l}\text { fine group structure using gamma } \\
\text { discrete line decay library }\end{array}$ & 1000 \\
\hline coarse & $\begin{array}{l}\text { coarse group structure using gamma } \\
\text { discrete line decay library }\end{array}$ & 10000 \\
\hline
\end{tabular}


The parameters tst, signif, epsm, epsn and exponmax assume floating point numbers; the remaining parameters assume integer numbers as input. To use the CINDER2008 defaults for the values of tst, signif, epsm, epsn, and exponmax, the user can either not specify values for those variables at all, or specify them as 0.0 (in which case the AARE_ACTIVATION will not change the CINDER2008 defaults).

The CINDER2008 default values for $t$ st and signif are 1e-12. The variables epsn, and exponmax are given by computer platform and compiler settings, epsm will be set to $100^{*}$ epsn. The user can use lower values of $t$ st and signif, in case higher precision calculations are needed. This, however, comes with increased execution times for the CINDER2008. The parameters fine and coarse define the group structure of the decay gamma decay sources reported in the CINDER2008 output files spectra_ts_decay and spectra_activity. The parameter fine provides the fine-group bin width in units of $\mathrm{eV}$, the parameter coarse defines the maximum energy bin with in units of $\mathrm{eV}$ into which neighboring zero entry fine groups are merged.

The following additional parameters are provided through the cinder_options block:

\begin{tabular}{|c|c|c|}
\hline Keyword & Description & Defaults \\
\hline wspect & $\begin{array}{l}\text { weighting spectrum used for } \\
\text { re-binning the neutron fluxes } \\
\text { ( } 0=\text { flat, } 1=\text { spallation, } \\
2=\text { fission, } 3=\text { fusion) }\end{array}$ & 1 \\
\hline library & $\begin{array}{l}\text { file name including path of the } \\
\text { library-file }\end{array}$ & $\begin{array}{l}\text { /usr/local/aare/data/C08lib_flat } \\
\text { or as modified by the AARE } \\
\text { installation script }\end{array}$ \\
\hline cxupdate & $\begin{array}{l}\text { file name including path of the } \\
\text { cxupdate-file }\end{array}$ & none \\
\hline cindergl & $\begin{array}{l}\text { file name including path of the } \\
\text { file cindergl.dat }\end{array}$ & none \\
\hline itsord & $\begin{array}{l}\text { times step number used for } \\
\text { ordering the tables by nuclide; } \\
\text { if } 0 \text { the last time step is used }\end{array}$ & 0 \\
\hline post & $\begin{array}{l}\text { switch to trigger a POST run } \\
\text { following the next } \\
\text { CINDER2008 run; 1/0 POST } \\
\text { run on/off }\end{array}$ & 0 \\
\hline
\end{tabular}

The additional parameter wspect allows choosing a weighting spectrum for regrouping the MCNPX neutron fluxes to the CINDER2008 multigroup energy structure.

The parameters library, cxupdate, and cindergl hold the file name (optionally including path name) of the "library", "cxupdate", and "cindergl.dat" files being used in the AARE_ACTIVATION generated "locate" file. Absolute path names or path names relative to the working directory are permitted. The first and second lines of the locate file contain the library and cxupdate name (including the full path), respectively. The library file will be read by the CINDER2008 code. The "cxupdate" file allows for userprovided problem-specific replacements of activation cross sections to be used by the 
CINDER2008 code instead of the default library entries. The user also has the option to pass library and cxupdate file names through the environment variables CINDERLIB, CINDERCXU, CINDERGL, and CINDERBZ to AARE_ACTIVATION. The script expects the environment variable CINDERBZ to hold the file name, including absolute path name or path name relative to the working directory. These environment variables override the defaults programmed into AARE_ACTIVATION itself. The file names provided through the AARE_ACTIVATION input file override these environment variables (or the defaults) such that the input file entries have precedence in any case. The parameter itsord provides the time step number used for sorting some of the tables by nuclide.

The user can combine results from multiple CINDER2008 runs using the POST code. The selection of CINDER2008 runs to be combined to an entity is forced by the parameter post. If post is set to 1, the current cell is added to the entity, and otherwise not. The execution of the POST code is controlled by the post_options block described in the next subsection.

All the parameters can be input in any order.

\subsection{POST_OPTIONS:}

POST is a tool that allows combining results from single CINDER2008 runs to provide CINDER2008 radionuclide tables and spectra files for an entity. For each CINDER2008 run with cinder_options parameter post set to 1, CINDER2008 enters information into the files "vols" and "post_locate" that are automatically generated and updated by CINDER2008. The post_options block is entered prior to the last cell_list block that contributes to an entity.

This block provides parameter settings used for a POST run:

\begin{tabular}{|l|l|l|}
\hline Keyword & Description & Defaults \\
\hline run & $\begin{array}{l}\text { switch to initiate a POST run (1) or } \\
\text { deactivate POST runs (0) }\end{array}$ & 0 \\
\hline postdir & $\begin{array}{l}\text { a string to be used to form a } \\
\text { directory name for saving the result } \\
\text { files of a POST run }\end{array}$ & "ostdir") \\
\hline thcat3 & $\begin{array}{l}\text { a string pointing to a file, which } \\
\text { contains user-provided thcat3 values } \\
\text { to replace the library thcat3 values }\end{array}$ & "'" \\
\hline
\end{tabular}

POST is executed following each CINDER2008 run when the parameter post is set to 1 . The results of a POST run are provided in directory "postdir".

\subsection{AAT_OPTIONS:}

The accident analysis tool (AAT) performs hazard classification analyses as described in the CINDER2008 manual. It is strongly recommended that the user familiarizes 
her/himself with the terminology of the Accident Analysis Tool before using it through AARE_ACTIVATION. AARE_ACTIVATION prepares the required input file dose_input.dat, which the CINDER2008 code uses to generate the accident dose and radionuclide threshold tables in the files "tables_dose" and "tables_threshold", respectively.

The block provides all inputs required to define dose_input.dat:

\begin{tabular}{|c|c|c|}
\hline Keyword & Description & Defaults \\
\hline run & $\begin{array}{l}\text { switch to initiate an AAT run } \\
\text { (on/off=1/0) }\end{array}$ & 0 \\
\hline warning & $\begin{array}{l}\text { string holding the logical value '.true.' } \\
\text { or '.false.'; turns on/off warning } \\
\text { messages to be printed by AAT }\end{array}$ & false. \\
\hline$d f \_d e f a u l t$ & $\begin{array}{l}\text { real value of Dispersion Factor DF } \\
\text { applied to all radionuclides for which } \\
\text { no specific value is given by file }\end{array}$ & 0 \\
\hline time ratio default & value of $T_{E} / T_{R}$ & 0 \\
\hline dr_default & $\begin{array}{l}\text { real value of Damage Ratio DR applied } \\
\text { to all radionuclides for which no } \\
\text { specific value is given by file }\end{array}$ & 0 \\
\hline arf_default & $\begin{array}{l}\text { real value of Airborne Release Fraction } \\
\text { ARF applied to all radionuclides for } \\
\text { which no specific value is given by file }\end{array}$ & 0 \\
\hline lpf_default & $\begin{array}{l}\text { real value of Leak Path Fraction LPF } \\
\text { applied to all radionuclides for which } \\
\text { no specific value is given by file }\end{array}$ & 0 \\
\hline br_default & $\begin{array}{l}\text { real value of Breathing Rate BR applied } \\
\text { to all radionuclides for which no } \\
\text { specific value is given by file }\end{array}$ & 0 \\
\hline oi_filename & string of other input filename & “" \\
\hline oi_format1 & $\begin{array}{l}\text { string of FORTRAN90 style read } \\
\text { statement for reading the other_input } \\
\text { data file }\end{array}$ & “"” \\
\hline oi_spec & $\begin{array}{l}\text { string of column headers for data } \\
\text { provided in other_input data file }\end{array}$ & “" \\
\hline dcf_i_default & $\begin{array}{l}\text { real value of Dose Conversion Factor } \\
\text { DCF applied to all radionuclides for } \\
\text { which no specific value is given by file }\end{array}$ & 0 \\
\hline dose_unit & Unit of Dose Equivalent & “"” \\
\hline di_ranked & $\begin{array}{l}\text { logical; '.true.' = rank dose tables in } \\
\text { descending order on the value of itsord } \\
\text { (see CINDER_OPTIONS); '.false.' }= \\
\text { standard Z/A ordering }\end{array}$ & “" \\
\hline di filename & string of $d c f$ input filename & “" \\
\hline
\end{tabular}




\begin{tabular}{|c|c|c|}
\hline di_format1 & $\begin{array}{l}\text { string of FORTRAN90 style read } \\
\text { statement for reading the } d c f \text { input data } \\
\text { file }\end{array}$ & "'" \\
\hline di_spec & $\begin{array}{l}\text { string of column headers for data } \\
\text { provided in di_filename }\end{array}$ & ،"' \\
\hline threshold_default & $\begin{array}{l}\text { real value of activity threshold applied } \\
\text { to all radionuclides for which no } \\
\text { specific value is given by file }\end{array}$ & 0 \\
\hline ti_ranked & $\begin{array}{l}\text { logical; '.true.' = rank dose tables in } \\
\text { descending order on the value of itsord } \\
\text { (see CINDER_OPTIONS); '.false.' = } \\
\text { standard Z/A ordering }\end{array}$ & 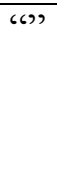 \\
\hline ti filename & string of threshold_input filename & 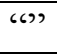 \\
\hline ti_format1 & $\begin{array}{l}\text { string of FORTRAN90 style read } \\
\text { statement for reading the } \\
\text { threshold_input data file }\end{array}$ & (') \\
\hline ti_spec & $\begin{array}{l}\text { string of column headers for data } \\
\text { provided in } t i \text { filename }\end{array}$ & “" \\
\hline
\end{tabular}

The contents of oi_filename, di_filename, and ti_filename are expanded to include the full path if local names are provided. AARE_ACTIVATION checks for the existence and readability of the files, and returns an error if the full names exceed 80 characters. The user may have to change the lengths allocated to the FILENAME and BLANK_LINE variables in the CINDER2008 module dose_mod.f90 if shortening the actual names does not help.

\subsection{ORIHET_OPTIONS:}

This block provides parameter settings used by the ORIHET3 code. Providing the orihet_options without any entries resets all values to the defaults. Providing the block name also causes the activation calculations to be performed using the ORIHET3 code unless is superseded by a cinder_options or fispact_options block before the next cell_list block:

\begin{tabular}{|c|c|c|}
\hline Keyword & Description & Defaults \\
\hline library & $\begin{array}{l}\text { choice of decay library to use ("nubasex" or } \\
\text { "orihet") }\end{array}$ & "nubasex" \\
\hline $\operatorname{actxs}$ & $\begin{array}{l}\text { choice of activation cross section library to } \\
\text { use: ("eaf" or "fendl_all.dat" or } \\
\text { "eaf2003cont.dat" or "eaf-xs-20050") } \\
\text { (default "fendl_all.dat") }\end{array}$ & "fendl_all.dat" \\
\hline lpath & pathname of activation cross section library & (6) \\
\hline xsversion & $\begin{array}{l}\text { option of EAF library }(1=\text { eaf-2001 / } 2=\text { eaf- } \\
2003,3=\text { eaf-2007 } / \quad 4=\text { eaf-2010) }\end{array}$ & 1 \\
\hline ngroup & $\begin{array}{l}\text { group structure of activation cross section } \\
(0 / 69 / 100 / 172 / 175 / 211 / 315 / 351)\end{array}$ & 0 \\
\hline
\end{tabular}




\begin{tabular}{|l|l|l|}
\hline wspect & $\begin{array}{l}\text { type of weighting spectrum used for } \\
\text { collapsing the EAF continuous data to } \\
\text { multigroup data( } 0=\text { flat,2=fission,3=fusion })\end{array}$ & 0 \\
\hline
\end{tabular}

The keyword library gives the choice of the decay library that the ORIHET3 code will use for the activation calculation, which can be "nubasex" or "orihet". The choice "nubasex" uses the latest ORIHET3 library based on the NUBASE evaluation with 3738 nuclides and 40 decay modes. The choice "orihet" selects the original ORIHET library with 2456 nuclides and 7 decay modes and provides the option to run ORIHET 3 in the old mode. The default is "nubasex".

The option actxs defines which activation cross section to use for the neutron flux driven neutron activation. The choice "fendl_all.dat", "eaf2003cont.dat" or "eaf-xs-20050" specifies the continuous energy FENDLA $/ 1.1^{9}$ library, or the linearized continuous EAF2003 or EAF2005 libraries, respectively.

WARNING: The FENDLA/1.1 library includes no information for actinides.

Calling the continuous energy ligraries "fendl_all.dat", eaf2003cont.dat" or "eaf-xs20050" with option actxs disregards options ngroup and xsversion. In this scheme AARE_ACTIVATION collapses the activation cross sections to the group structure provided by the MCNPX neutron fluxes, before folding fluxes with cross sections to obtain isotope production rates. The variable lpath provides the directory name that holds the cross section libraries.

The choice "eaf" with the actxs option triggers the use of multigroup activation cross sections provided by the EASY-2010 package. The option xsversion choses between the EAF-2001 ${ }^{10}$, the EAF-2003 ${ }^{11}$, EAF-2007, or EAF-2010 cross section base. The option ngroup requests a certain multigroup energy structure, and the option wspect requests a certain weighting spectrum for the collapse of the multigroup cross section library. The three options xsversion, ngroup, and wspect define the EASY-2010 library that AARE_ACTIVATION picks to calculate the flux based isotope production rates. If the neutron fluxes from the MCNPX output do not correspond to the requested group structure, AARE_ACTIVATION rebins the fluxes using the spectrum type given by wspect. The EASY-2010 package does not provide libraries in all ngroup and wspect combinations. The supported combinations of energy group structure and weighting spectra for both the EAF-2001, through EAF-2010 cross section bases are as follows:

\begin{tabular}{|l|l|l|l|}
\hline \multirow{2}{*}{ Groups } & \multicolumn{3}{|l|}{ Neutron Spectrum for Cross Section Collapse } \\
\cline { 2 - 4 } & Flat & Fission & Fusion \\
\hline 69 & & $\mathrm{X}$ & \\
\hline 100 & & & $\mathrm{X}$ \\
\hline 172 & $\mathrm{X}$ & $\mathrm{X}$ & \\
\hline 175 & $\mathrm{X}$ & & $\mathrm{X}$ \\
\hline 315 & $\mathrm{X}$ & $\mathrm{X}$ & $\mathrm{X}$ \\
\hline
\end{tabular}

For EAF-2007 and EAF-2010 the following additional options are offered extending the upper energy limit of the cross sections to $60 \mathrm{MeV}$ : 


\begin{tabular}{|l|l|l|l|}
\hline \multirow{2}{*}{ Groups } & \multicolumn{4}{|l|}{ Neutron Spectrum for Cross Section Collapse } \\
\cline { 2 - 4 } & Flat & Fission & Fusion \\
\hline 211 & $\mathrm{X}$ & & \\
\hline 351 & $\mathrm{X}$ & & \\
\hline
\end{tabular}

The use of deuteron and proton induced activation cross section of EAF-2007 is not yet supported in combination with the ORIHET3 code.

\subsection{FISPACT_OPTIONS:}

This block provides parameter settings used by the FISPACT code. Providing the fispact_options without any entries resets all values to the defaults. Providing the block name also causes the activation calculations to be performed using the FISPACT code unless a cinder_options or orihet_options block appears before the next cell_list block.

\begin{tabular}{|c|c|c|}
\hline Keyword & Description & Defaults \\
\hline fispact root & path to EASY-2010 cross section directory & “"” \\
\hline xsversion & $\begin{array}{l}\text { option of EAF library (1=EAF-2001, 2=EAF- } \\
\text { 2003, 3=EAF-2007, 4=EAF-2010) }\end{array}$ & 4 \\
\hline ngroup & $\begin{array}{l}\text { multigroup structure of activation cross } \\
\text { section }(0 / 69 / 100 / 172 / 175 / 211 / 315 / 351)\end{array}$ & 175 \\
\hline wspect & $\begin{array}{l}\text { type of weighting spectrum used for } \\
\text { collapsing the EAF continuous data to } \\
\text { multigroup data }(0=\text { flat }, 2=\text { fission, } 3=\text { fusion })\end{array}$ & 0 \\
\hline projectile & neutrons, deuterons or protons $(1 / 2 / 3)$ & 1 \\
\hline nostab & enable/disable (0/1) plotting of stable isotopes & 1 \\
\hline dose & $\begin{array}{l}\text { choice of dose rate calculation }(0=\text { semi } \\
\text { infinite slab, } 1=\text { point dose } 1 \text { meter distance) }\end{array}$ & 0 \\
\hline ftabl & unit number for writing a TAB1 file & 0 \\
\hline ftab2 & unit number for writing a TAB2 file & 0 \\
\hline ftab3 & unit number for writing a TAB3 file & 0 \\
\hline ftab4 & unit number for writing a TAB4 file & 0 \\
\hline printlib & $\begin{array}{l}\text { enable/disable (1/0) writing one-group cross } \\
\text { section file }\end{array}$ & 0 \\
\hline mind & $\begin{array}{l}\text { minimum number of atoms considered above } \\
\text { zero }\end{array}$ & $1 \mathrm{e} 5$ \\
\hline clear & clearance calculated $($ on $/$ off $=1 / 0)$ & 0 \\
\hline clear file & $\begin{array}{l}\text { file of clearance levels }(\mathrm{Bq} / \mathrm{kg}) \text { to be used for } \\
\text { clearance estimation }\end{array}$ & 0 \\
\hline
\end{tabular}

The variable lpath provides the directory name that holds the cross section libraries.

The option xsversion choses between the EAF-2001, EAF-2003, EAF-2007, and EAF2010 cross section etc. The option ngroup requests a certain multigroup structure, and the option wspect a certain weighting spectrum, for the collapse of the multigroup cross section library. The three options xsversion, ngroup, and wspect define the EASY-2010 library that 
AARE_ACTIVATION picks to calculate the isotope production rates. If the neutron fluxes energy group structure from the MCNPX output does not correspond to the requested group structure, AARE_ACTIVATION regroups the fluxes using the spectrum type given by wspect. The EASY-2010 package does not provide libraries in all ngroup and wspect combinations. The supported combinations for both the EAF-2001 through EAF-2010 cross section sets are as follows:

\begin{tabular}{|l|l|l|l|}
\hline \multirow{2}{*}{ Groups } & \multicolumn{4}{|l|}{ Neutron Spectrum for Cross Section Collapse } \\
\cline { 2 - 4 } & Flat & Fission & Fusion \\
\hline 69 & & $\mathrm{X}$ & \\
\hline 100 & & & $\mathrm{X}$ \\
\hline 172 & $\mathrm{X}$ & $\mathrm{X}$ & $\mathrm{X}$ \\
\hline 175 & $\mathrm{X}$ & & $\mathrm{X}$ \\
\hline 315 & $\mathrm{X}$ & $\mathrm{X}$ & \\
\hline
\end{tabular}

For EAF-2007 and EAF-2010 the following additional options are offered extending the upper energy limit of the cross sections to $60 \mathrm{MeV}$ :

\begin{tabular}{|l|l|l|l|}
\hline \multirow{2}{*}{ Groups } & \multicolumn{3}{|l|}{ Neutron Spectrum for Cross Section Collapse } \\
\cline { 2 - 4 } & Flat & Fission & Fusion \\
\hline 211 & $\mathrm{X}$ & & \\
\hline 351 & $\mathrm{X}$ & & \\
\hline
\end{tabular}

The variable projectile selects neutrons, protons, or deuterons as the radiation field causing activation and transmutation. Spallation products are considered in combination with neutron projectiles, while deuteron and proton projectiles disregard spallation products even when requested (through the RUN_OPTIONS block). The projectile settings of 2 and 3 require $x$ sversion $=3$ or 4 , ngroup $=211$, and wspect $=0$.

AARE_ACTIVATION execution returns with an error message if these settings are not provided.

The nostab code word enables (0) or disables (1) the output of stable nuclides in FISPACT. With dose $n$ and a value $n \geq 1$ the point dose of 1 gram of material at a distance of $n$ meters is calculated.

If ftab1, ftab2, ftab3, or ftab4 are enabled by providing file unit numbers, separate files containing selected calculational information will be produced:

\begin{tabular}{|l|l|l|}
\hline Table & Information & File Unit \\
\hline TAB1 & Number of atoms and Mass & $>43$ \\
\hline TAB2 & Nuclide activity and dose rate & $>44$ \\
\hline TAB3 & Nuclide ingestion and inhalation dose & $>45$ \\
\hline TAB4 & 24 energy group gamma-ray spectrum & $>46$ \\
\hline
\end{tabular}

The file unit numbers must be larger than the values given in the above table. 
With the printlib code word the decay database and the one group cross sections produced by FISPACT will be printed to the printlib.out file.

Setting the parameter clear to 1 initiates a clearance estimate based on the clearance coefficients provided by the EAF_clear file associated with the respective sublibrary. The file name of user-provided clearance coefficients can be provided with the parameter clear_file, which will replace the library provided version.

\subsection{NORMALIZATION:}

This block carries the parameter snorm, which provides the normalization constant for the fluxes and the isotope production and destruction rates:

- snorm (no default is given, urging the user to think about normalization)

\subsection{HISTORY:}

This block provides the activation history. It reads sub-blocks of time steps:

$$
\begin{aligned}
& \begin{array}{llllllll}
N_{1} & P_{1} & T_{11} & U_{11} & T_{12} & U_{12} & \ldots & T_{1 N 1} U_{1 N 1}
\end{array} \\
& \begin{array}{lllllllll}
N_{2} & P_{2} & T_{21} & U_{21} & T_{22} & U_{22} & \ldots & T_{2 N 2} U_{2 N 2}
\end{array}
\end{aligned}
$$

with $N_{i}$ and $P_{i}$ giving the number of time steps and the normalization factor in sub-block $i$, and the combinations $T_{i j} U_{i j}$ giving the time step and the time unit, respectively. In any given time step, the overall normalization factor is the product of snorm, provided in the normalization block, and $N_{i}$.

A blank line terminates the history block. Positive and negative values can be used for the time steps $T_{i j}$; positive values meaning increments of time with regard to the previous time step, and negative values meaning absolute time. The time units $U_{i j}$ can be $s, m, h, d, w, y$ for seconds, minutes, hours, days, weeks and years, respectively. For these purposes, a year is defined as 365.24 days.

For ORIHET problems, additional decay time steps of $1 \mathrm{~ns}$ length are introduced by the script to force ORIHET to re-initialize its isotope production rate arrays for each buildup sub-block.

\subsection{CELL_LIST:}

This block inputs any number of cells the material, flux and isotope production/destruction information of which will be combined into a region average. A comment line is followed by lines of cell numbers for which an activation calculation shall be performed.

WARNING: No checks are performed with respect to the material composition of each cell. Averaging over cells of different material may introduce serious errors because averaged fluxes are applied on averaged material compositions. 


\subsection{CL_FILE:}

In applications involving many cells, the setup of CELL_LIST blocks for each cell is cumbersome. In such cases the user can specify a list of cells separated by blanks given in a cell-file. The cell_file name is provided in the CL_FILE block with the sole parameter file:

\begin{tabular}{|l|l|l|}
\hline Keyword & Description & Defaults \\
\hline file & cell-file name & none \\
\hline
\end{tabular}




\section{EXAMPLE ACTIVATION SCRIPT INPUTS}

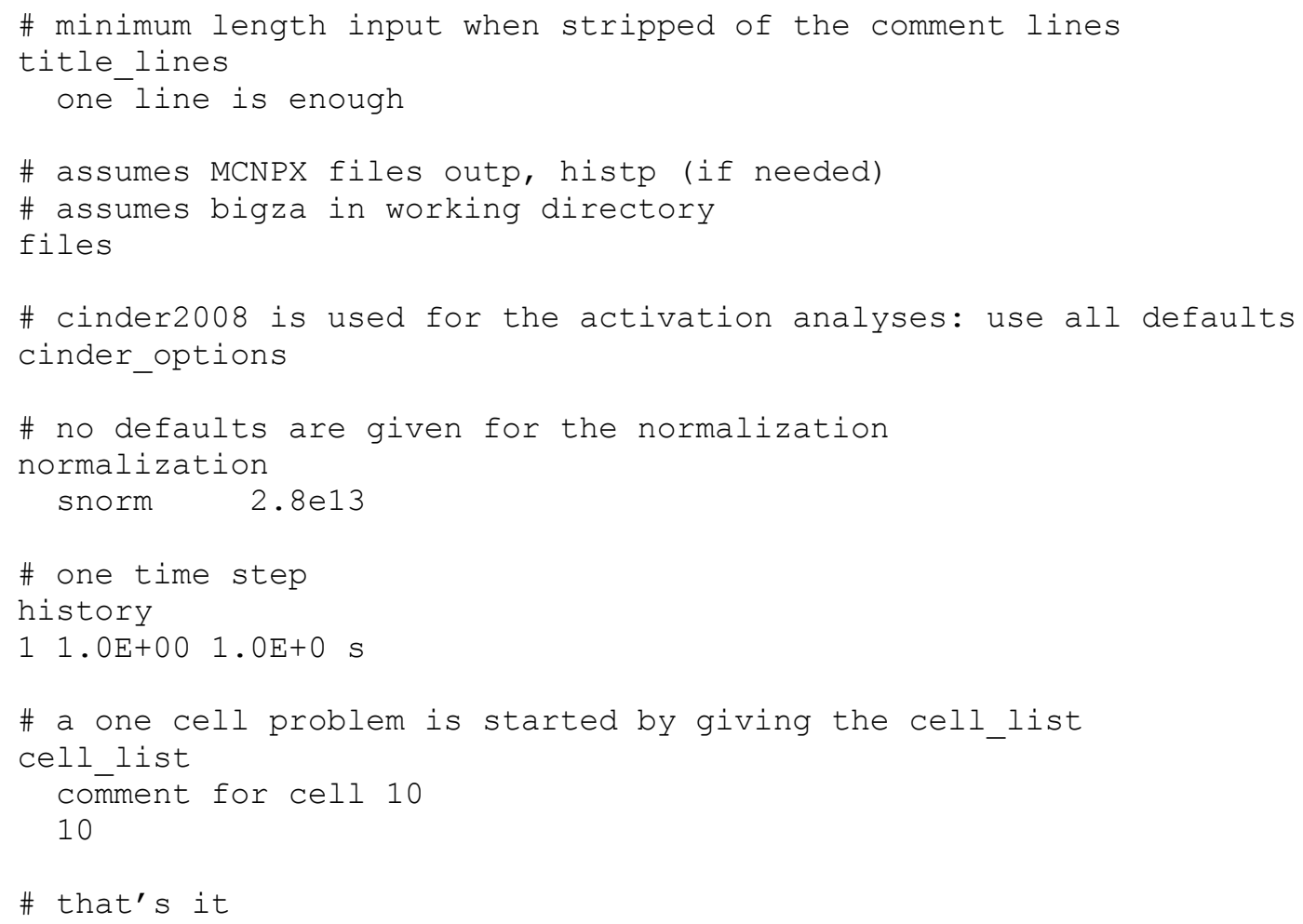




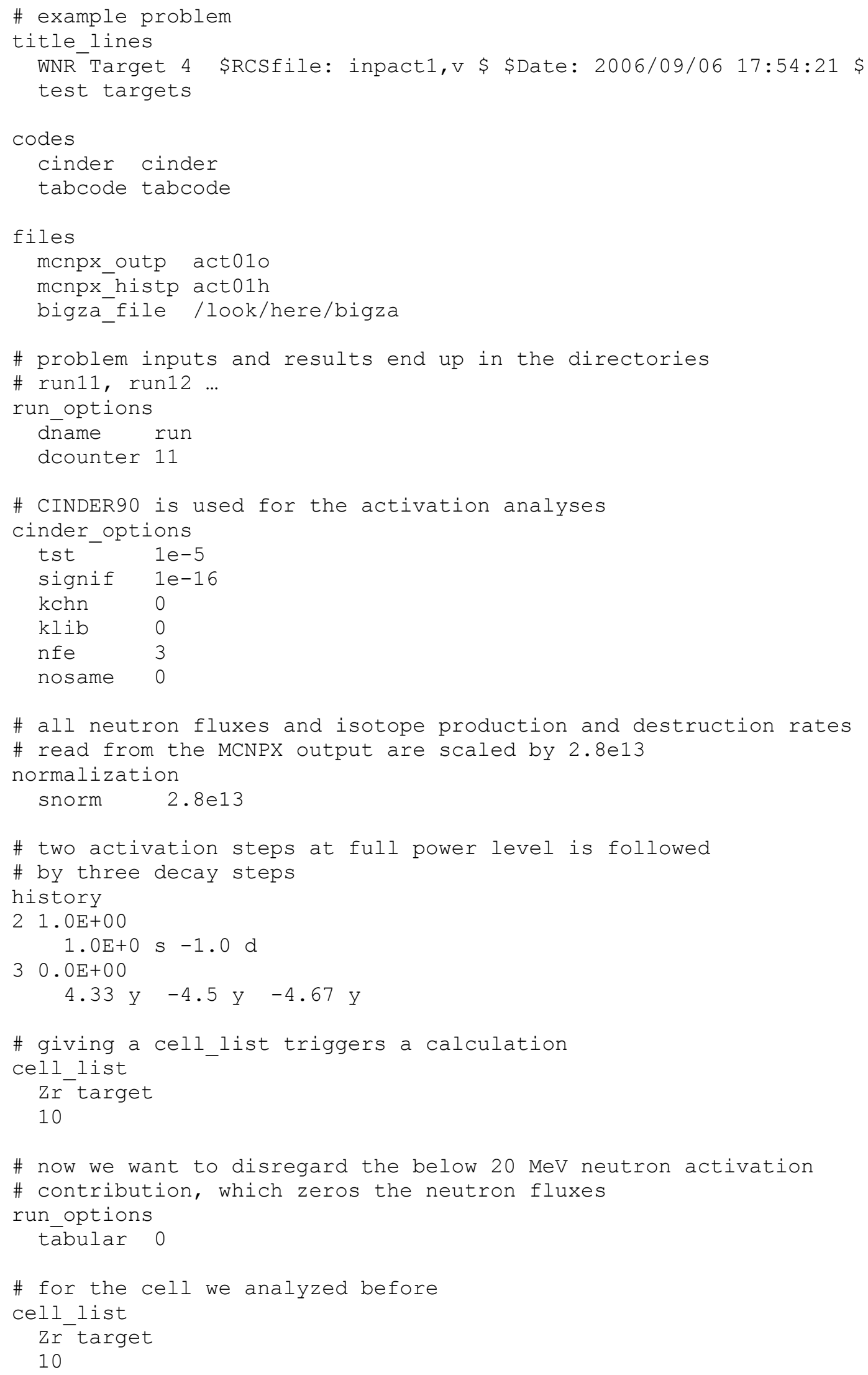




\section{EXECUTION}

AARE_ACTIVATION is executed by providing script input and script output file names through the script arguments:

aare_activation script_input script_output

Except for the output file, which contains run-time information and the results of intermediate steps of the calculation, AARE_ACTIVATION generates the problem specific output files in problem directories run_ $i$ for each instance of cell list read from the script_input file, with $i$ being consecutive numbers starting with 1 unless a different directory name and counter were specified in the run_options block. Each directory contains the input files generated by AARE_ACTIVATION for the requested activation code, as well as the output files resulting from the run with the requested activation code. One can rerun the activation calculations individually in the respective problem directory. AARE_ACTIVATION also provides a listing of all executed problems with directory name, volume, material density, and cell_list in the file cell_dir_vol_list. This file is updated and not overwritten by subsequent calculations. Intermediate output files, i.e. the files produced by HTAPE3X and/or GROUPIE, are also saved in the problem specific directories, if the parameter verbose in the block run_options was set to 1.

Building on the activation code output files of CINDER2008, FISPACT, and ORIHET, GAMMA_SOURCE extracts the decay gamma sources for a certain time step and a list of cells given by the file cell_dir_vol_list, and generates a source description for a MCNPX decay gamma calculation. GAMMA_SOURCE is described in the document Gamma Source Script User Guide ${ }^{15}$.

\section{CONTACTS AND ERROR REPORTS}

In case you encounter problems with the activation script, the authors would be pleased to receive a report, including inputs and code versions you were using, through cinderhelp@email.ornl.gov. We will try hard to come back to you with a fix as soon as time and our workload permits. 


\section{REFERENCES}

1. D. P. Pellowitz, MCNPX User's Manual Version 2.6.0, LA-CP-07-1473, Los Alamos National Laboratory, April 2008.

2. D. P. Pellowitz, MCNPX User's Manual Version 2.7.0, LA-CP-11-00438, Los Alamos National Laboratory, April 2011.

3. D. P. Pellowitz, MCNP6 User's Manual Version 1.0, LA-CP-13-00634, Los Alamos National Laboratory, May 2013.

4. S.T. Holloway et al, A Manual for Cinder2008 Codes and Data, LA-UR-1100006, Los Alamos National Laboratory, Los Alamos, (2011).

5. R. A. Forrest, FISPACT-2007: User Manual, UKAEA FUS 534, EURATOM/UKAEA, Abingdon, UK, February 2007.

6. C. Petrovich, A Computer Code for Activation and Decay Calculations for Intermediate Energies, A Connection of FISPACT with MCNPX, ENEA, Bologna, unità ETG-SIEC-FIRE (2001); contact M. Wohlmuther/PSI.

7. F. Achison and H. Schaal, ORIHET3-Version 1.12, A Guide for Users, PSI, Villigen, Switzerland (2003); contact M. Wohlmuther/PSI.

8. B. Pashchenko and P. K. McLaughlin, "FENDL/A-1.1, Neutron Activation Cross Section Data Library for Fusion Applications," IAEA-NDS-148, Rev. 2 (1995).

9. R. A. Forrest, J. Kopecky, J-Ch. Sublet, The European Activation File: EAF-2003 cross section library, UKAEA FUS 486, EURATOM/UKAEA, Abingdon, UK (2002).

10. R. A. Forrest, The European Activation File, EAF-2005, AIP Conference Proceedings 769, 157 (2005); doi: 10.1063/1.1944980.

11. D. E. Cullen, PREPRO 2010, https://www-nds.iaea.org/public/endf/prepro2010/

12. J-Ch. Sublet, L. W. Parker, J. Kopecky, R. A. Forrest,J. Koning, D.A. Rochman, The European Activation File: EAF-2010 neutron-induced cross section library, CCFE-R(10)05, EURATOM/CCFE Fusion Association, Abington, UK, April 2010.

13. R. A. Forrest, Activation File: EAF-2007 deuteron- and proton-induced cross section libraries, UKAEA FUS 536, EURATOM/UKAEA, Abingdon, UK, January 2007.

14. Wohlmuther, M., Gallmeier, F. X., Brugger, M., Roesler, Stefan, Activation Of Trace Elements And Impurities - A New Ansatz For Monte Carlo Calculations, Nuclear Technology, Vol. 168(3), p. 625 (2009).

15. M. Wohlmuther, F. X. Gallmeier, User Guide for the Gamma Source Perl Script 2.0, PSI, Villigen, Switzerland (2012). 
APPENDIX 1. CINDER2008 MULTI-GROUP ENERGY STRUCTURES

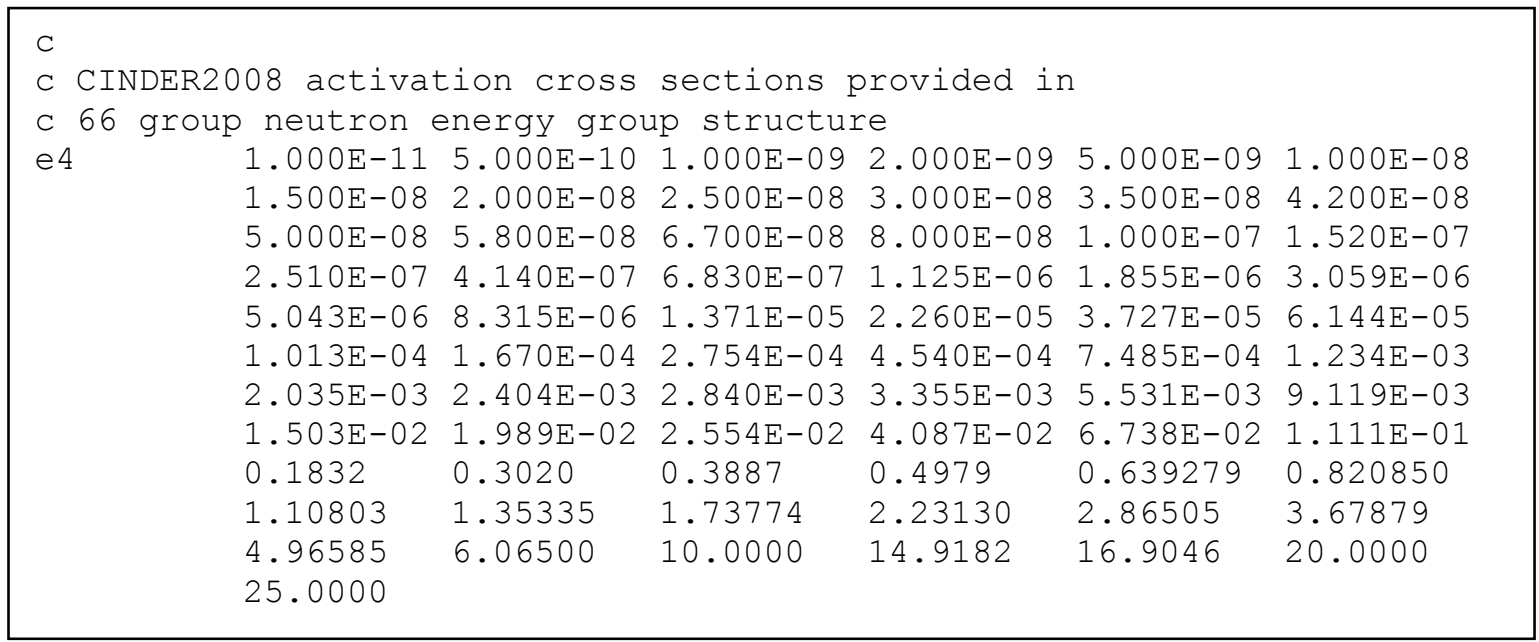




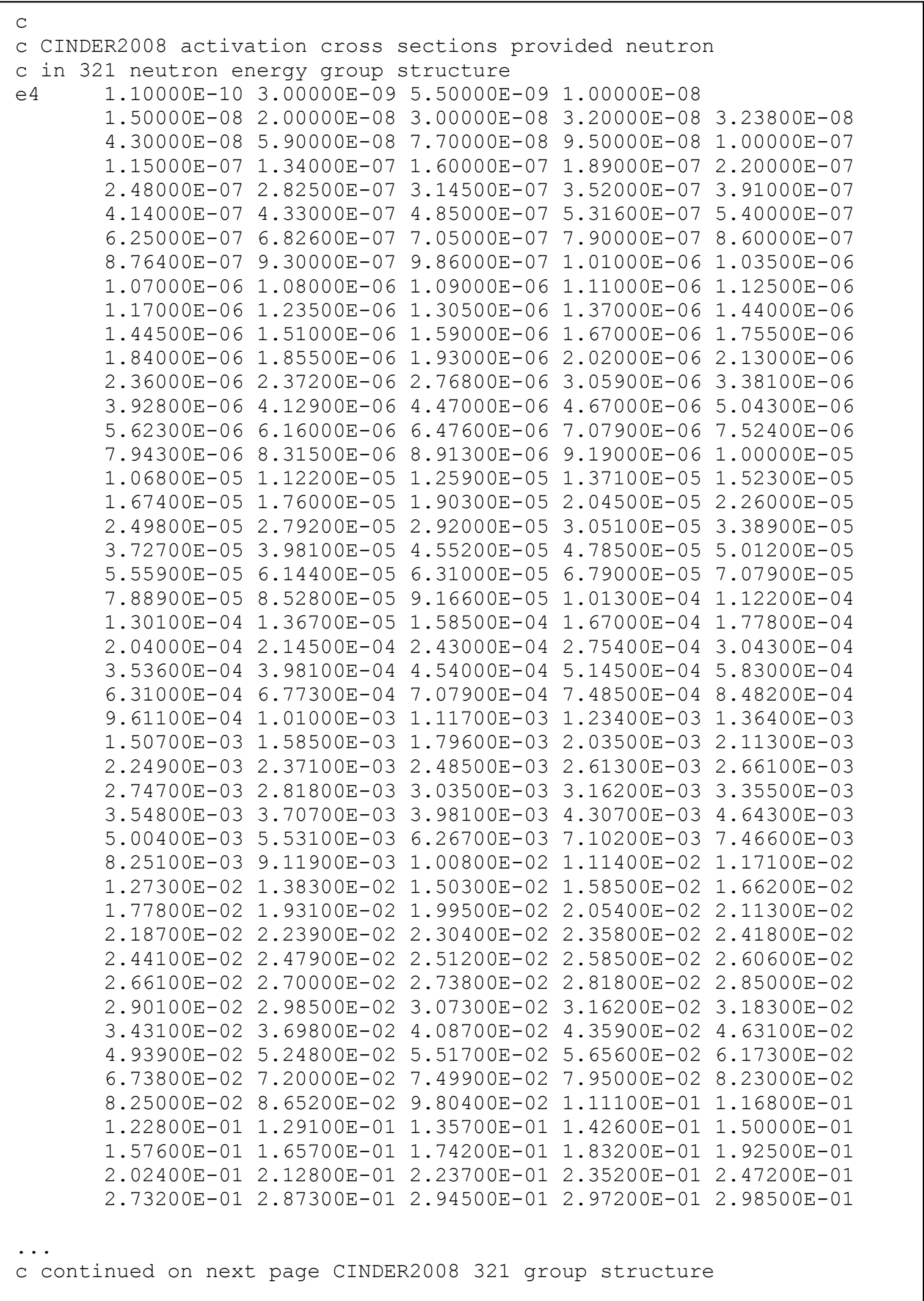




\begin{tabular}{|c|cccc|}
\hline c continues CINDER2008 321 group structure \\
$\ldots \ldots$ \\
$3.02000 \mathrm{E}-01$ & $3.33700 \mathrm{E}-01$ & $3.68800 \mathrm{E}-01$ & $3.87700 \mathrm{E}-01$ & $4.07600 \mathrm{E}-01$ \\
$4.50500 \mathrm{E}-01$ & $5.23400 \mathrm{E}-01$ & $5.50200 \mathrm{E}-01$ & $5.78400 \mathrm{E}-01$ & $6.08100 \mathrm{E}-01$ \\
$6.39300 \mathrm{E}-01$ & $6.72100 \mathrm{E}-01$ & $7.06500 \mathrm{E}-01$ & $7.42700 \mathrm{E}-01$ & $7.80800 \mathrm{E}-01$ \\
$8.20900 \mathrm{E}-01$ & $8.62900 \mathrm{E}-01$ & $9.07200 \mathrm{E}-01$ & $9.61600 \mathrm{E}-01$ & $1.00300 \mathrm{E}+00$ \\
$1.10800 \mathrm{E}+00$ & $1.16500 \mathrm{E}+00$ & $1.22500 \mathrm{E}+00$ & $1.28700 \mathrm{E}+00$ & $1.35300 \mathrm{E}+00$ \\
$1.42300 \mathrm{E}+00$ & $1.49600 \mathrm{E}+00$ & $1.57200 \mathrm{E}+00$ & $1.65300 \mathrm{E}+00$ & $1.73800 \mathrm{E}+00$ \\
$1.82700 \mathrm{E}+00$ & $1.92100 \mathrm{E}+00$ & $2.01900 \mathrm{E}+00$ & $2.12200 \mathrm{E}+00$ & $2.23100 \mathrm{E}+00$ \\
$2.30700 \mathrm{E}+00$ & $2.34600 \mathrm{E}+00$ & $2.36500 \mathrm{E}+00$ & $2.38500 \mathrm{E}+00$ & $2.46600 \mathrm{E}+00$ \\
$2.59200 \mathrm{E}+00$ & $2.72500 \mathrm{E}+00$ & $2.86500 \mathrm{E}+00$ & $3.01200 \mathrm{E}+00$ & $3.16600 \mathrm{E}+00$ \\
$3.32900 \mathrm{E}+00$ & $3.67900 \mathrm{E}+00$ & $4.06600 \mathrm{E}+00$ & $4.49300 \mathrm{E}+00$ & $4.72400 \mathrm{E}+00$ \\
$4.96600 \mathrm{E}+00$ & $5.22000 \mathrm{E}+00$ & $5.48800 \mathrm{E}+00$ & $5.76900 \mathrm{E}+00$ & $6.06500 \mathrm{E}+00$ \\
$6.37600 \mathrm{E}+00$ & $6.59200 \mathrm{E}+00$ & $6.70300 \mathrm{E}+00$ & $7.04700 \mathrm{E}+00$ & $7.40800 \mathrm{E}+00$ \\
$7.78800 \mathrm{E}+00$ & $8.18700 \mathrm{E}+00$ & $8.60700 \mathrm{E}+00$ & $9.04800 \mathrm{E}+00$ & $9.51200 \mathrm{E}+00$ \\
$1.00000 \mathrm{E}+01$ & $1.05100 \mathrm{E}+00$ & $1.10500 \mathrm{E}+01$ & $1.16200 \mathrm{E}+01$ & $1.22100 \mathrm{E}+01$ \\
$1.28400 \mathrm{E}+01$ & $1.35000 \mathrm{E}+01$ & $1.38400 \mathrm{E}+01$ & $1.41900 \mathrm{E}+01$ & $1.45500 \mathrm{E}+01$ \\
$1.49200 \mathrm{E}+01$ & $1.56800 \mathrm{E}+01$ & $1.64900 \mathrm{E}+01$ & $1.69100 \mathrm{E}+01$ & $1.73300 \mathrm{E}+01$ \\
$1.96400 \mathrm{E}+01$ & $2.00000 \mathrm{E}+01$ & $2.10000 \mathrm{E}+01$ & $2.20000 \mathrm{E}+01$ & $2.30000 \mathrm{E}+01$ \\
$2.40000 \mathrm{E}+01$ & $2.50000 \mathrm{E}+01$ & & & \\
\hline
\end{tabular}


APPENDIX 2: FISPACT MULTI-GROUP ENERGY STRUCTURES

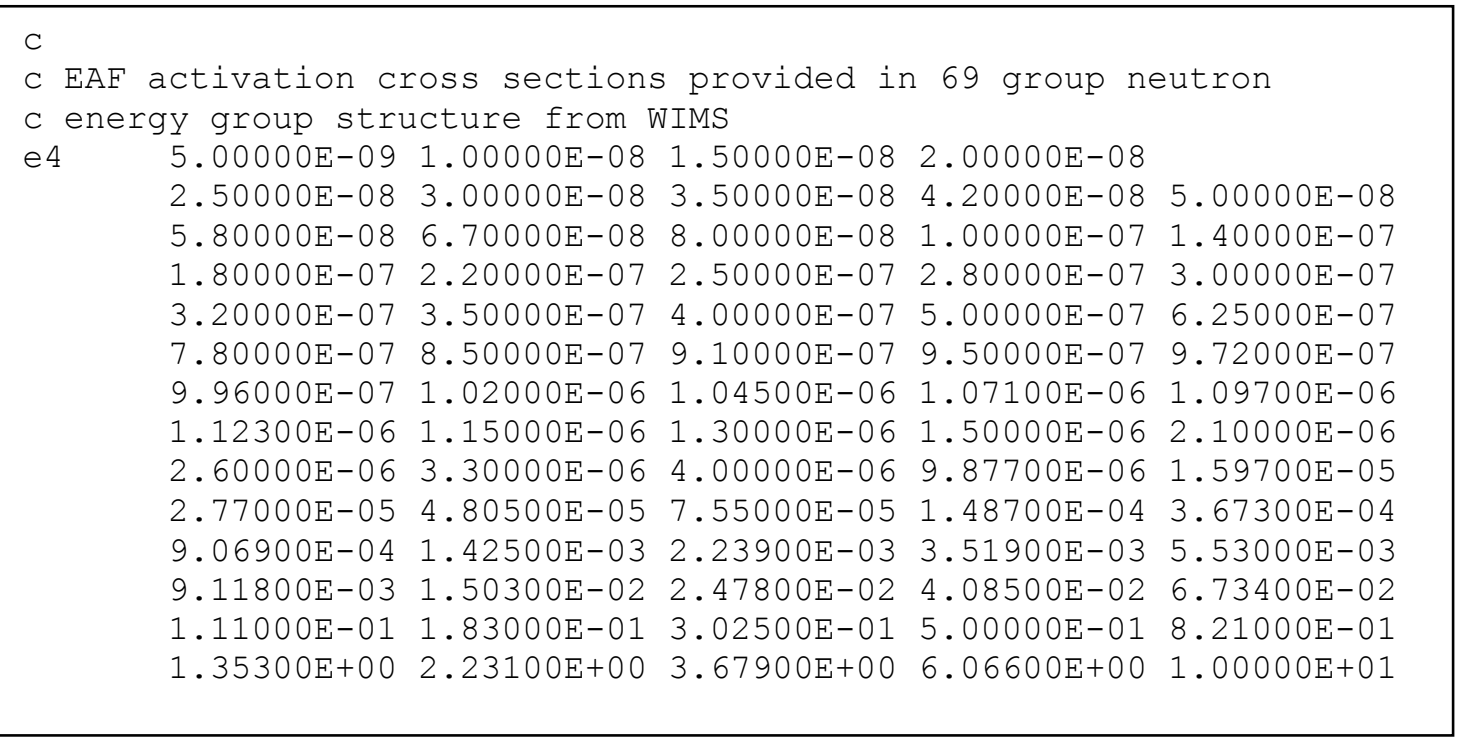




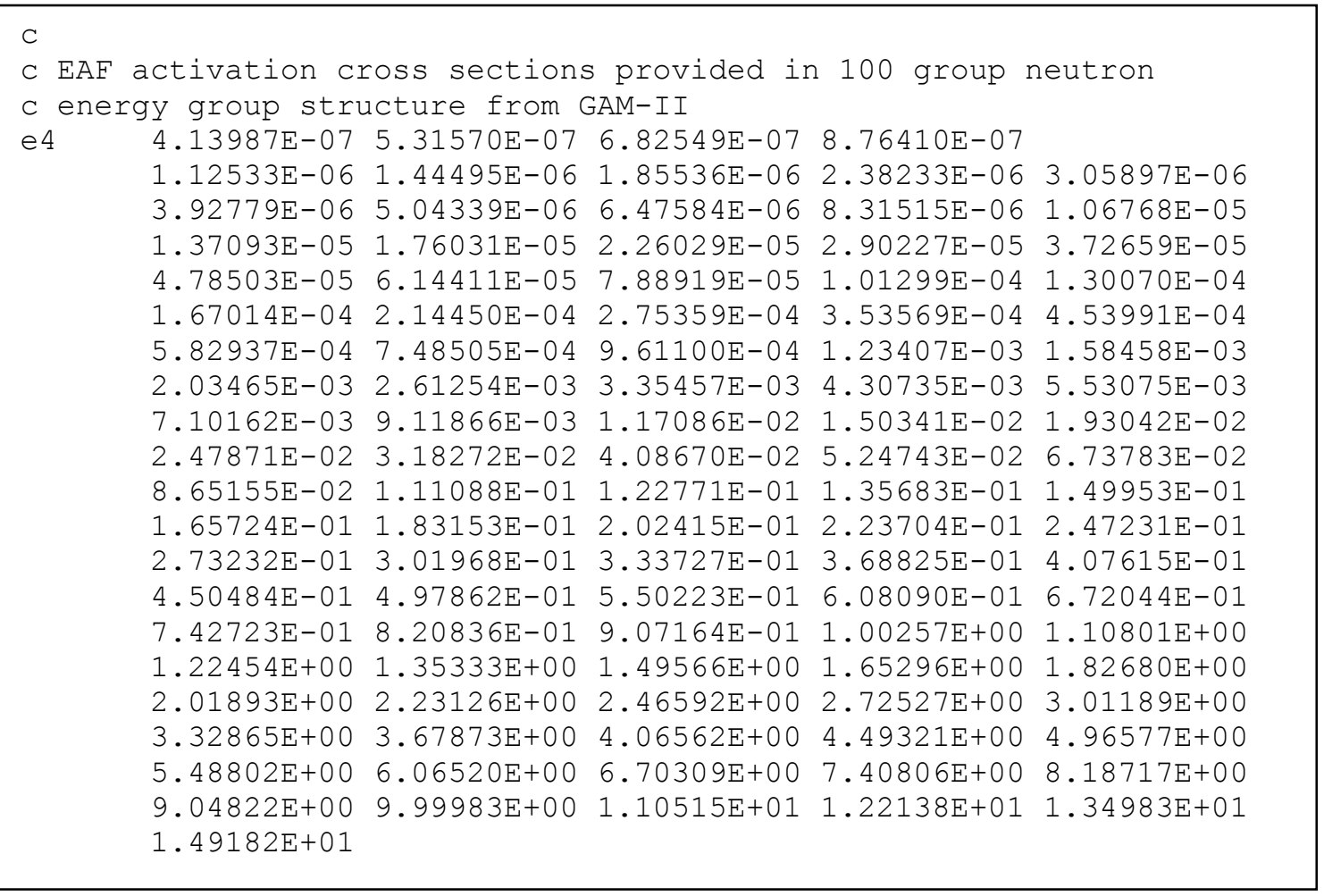




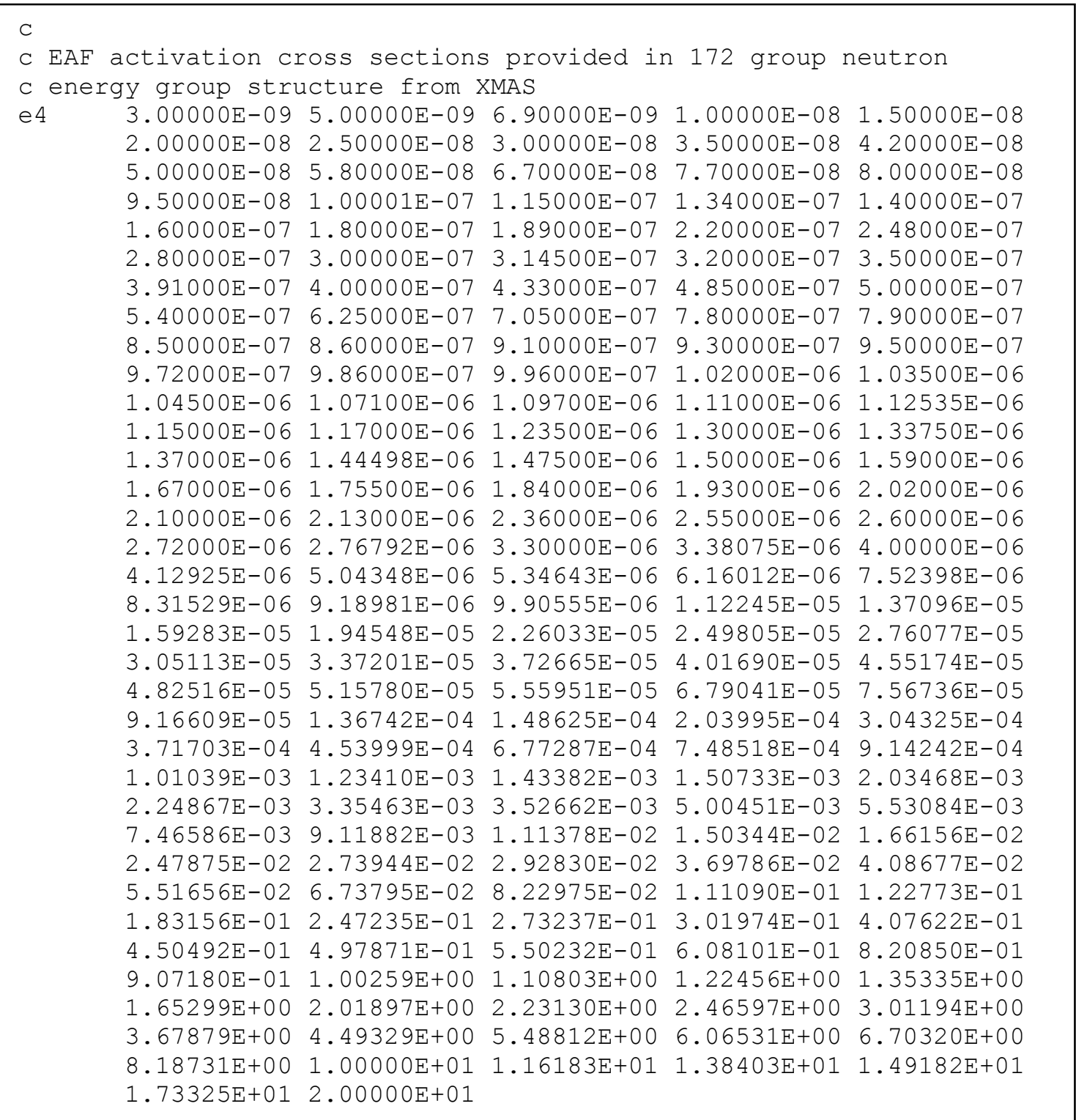




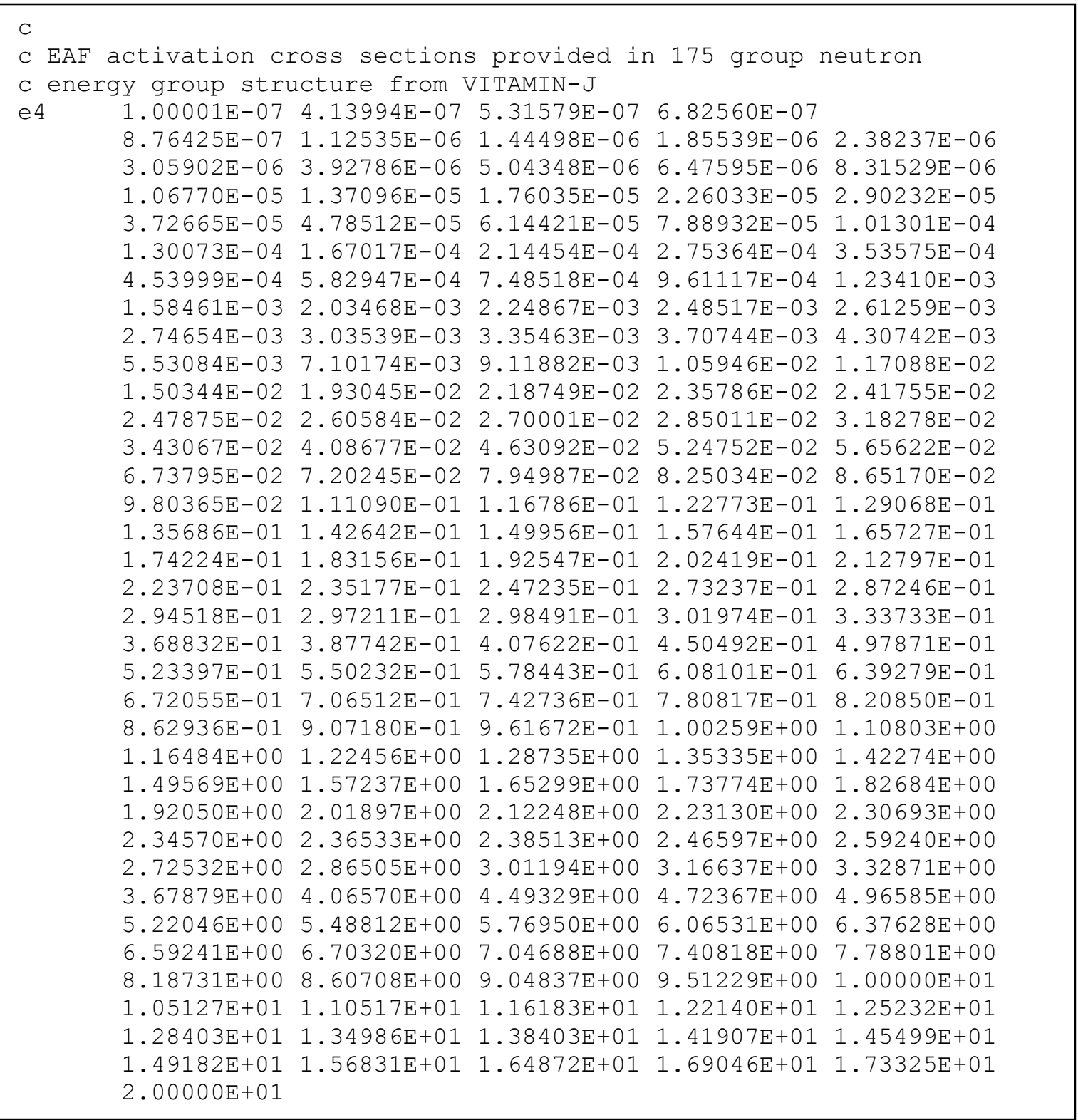




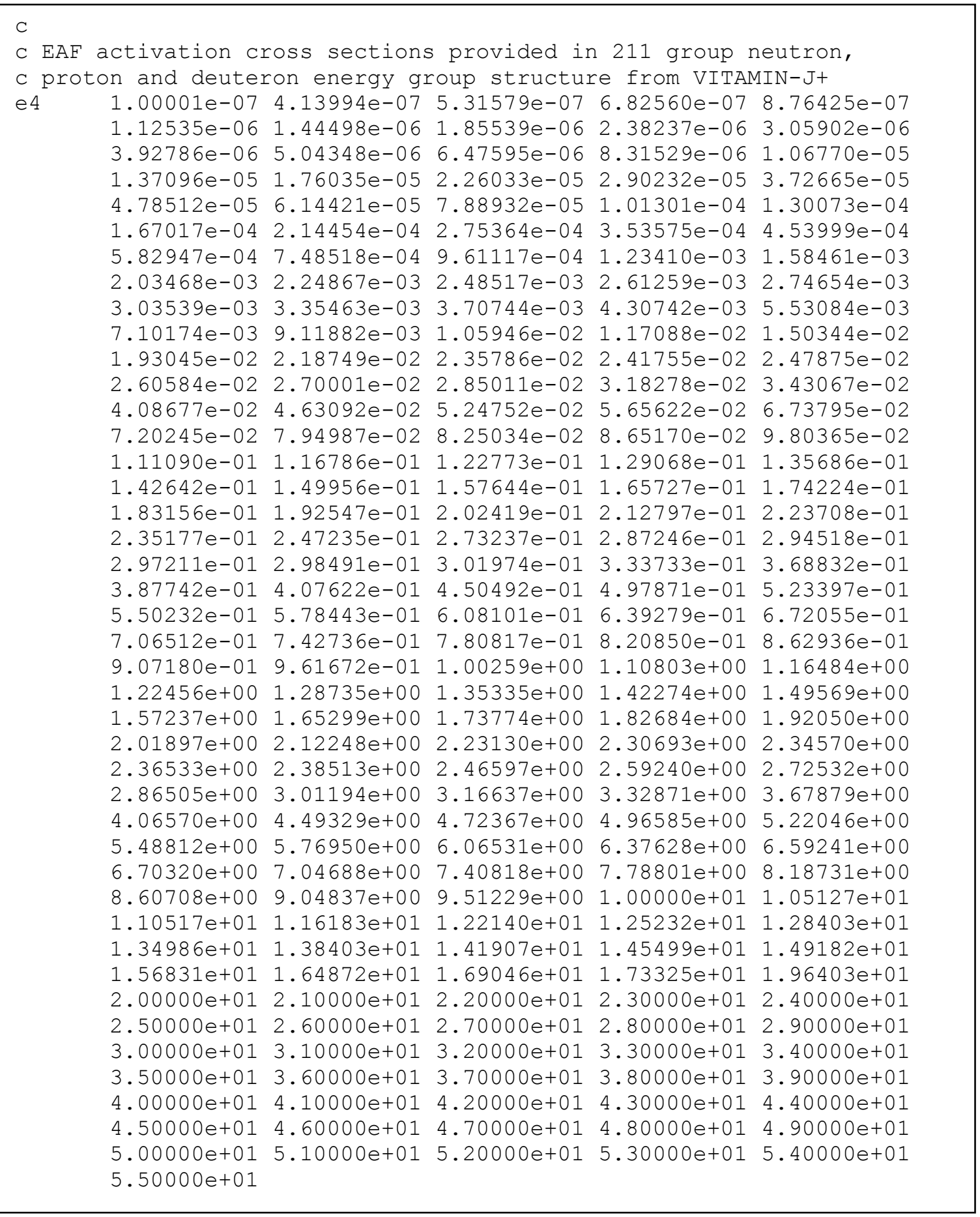


$c$

C EAF activation cross sections provided in 315 group neutron

c energy group structure from TRIPOLI

e4 $\quad 1.10000 \mathrm{E}-10 \quad 3.00000 \mathrm{E}-09 \quad 5.50000 \mathrm{E}-09 \quad 1.00000 \mathrm{E}-08$,

$1.50000 \mathrm{E}-08 \quad 2.00000 \mathrm{E}-08 \quad 3.00000 \mathrm{E}-08 \quad 3.20000 \mathrm{E}-08 \quad 3.23800 \mathrm{E}-08$

$4.30000 \mathrm{E}-08 \quad 5.90000 \mathrm{E}-08 \quad 7.70000 \mathrm{E}-08 \quad 9.50000 \mathrm{E}-08 \quad 1.00000 \mathrm{E}-07$

$1.15000 \mathrm{E}-07 \quad 1.34000 \mathrm{E}-07 \quad 1.60000 \mathrm{E}-07 \quad 1.89000 \mathrm{E}-07 \quad 2.20000 \mathrm{E}-07$

$2.48000 \mathrm{E}-07 \quad 2.82500 \mathrm{E}-07 \quad 3.14500 \mathrm{E}-07 \quad 3.52000 \mathrm{E}-07 \quad 3.91000 \mathrm{E}-07$

$4.14000 \mathrm{E}-07 \quad 4.33000 \mathrm{E}-07 \quad 4.85000 \mathrm{E}-07 \quad 5.31600 \mathrm{E}-07 \quad 5.40000 \mathrm{E}-07$

$6.25000 \mathrm{E}-07 \quad 6.82600 \mathrm{E}-07 \quad 7.05000 \mathrm{E}-07 \quad 7.90000 \mathrm{E}-07 \quad 8.60000 \mathrm{E}-07$

8.76400E-07 9.30000E-07 9.86000E-07 1.01000E-06 $1.03500 \mathrm{E}-06$

$1.07000 \mathrm{E}-06 \quad 1.08000 \mathrm{E}-06 \quad 1.09000 \mathrm{E}-06 \quad 1.11000 \mathrm{E}-06 \quad 1.12500 \mathrm{E}-06$

$1.17000 \mathrm{E}-06 \quad 1.23500 \mathrm{E}-06 \quad 1.30500 \mathrm{E}-06 \quad 1.37000 \mathrm{E}-06 \quad 1.44000 \mathrm{E}-06$

$1.44500 \mathrm{E}-06 \quad 1.51000 \mathrm{E}-06 \quad 1.59000 \mathrm{E}-06 \quad 1.67000 \mathrm{E}-06 \quad 1.75500 \mathrm{E}-06$

$1.84000 \mathrm{E}-06 \quad 1.85500 \mathrm{E}-06 \quad 1.93000 \mathrm{E}-06 \quad 2.02000 \mathrm{E}-06 \quad 2.13000 \mathrm{E}-06$

$2.36000 \mathrm{E}-06 \quad 2.37200 \mathrm{E}-06 \quad 2.76800 \mathrm{E}-06 \quad 3.05900 \mathrm{E}-06 \quad 3.38100 \mathrm{E}-06$

$3.92800 \mathrm{E}-06 \quad 4.12900 \mathrm{E}-06 \quad 4.47000 \mathrm{E}-06 \quad 4.67000 \mathrm{E}-06 \quad 5.04300 \mathrm{E}-06$

$5.62300 \mathrm{E}-06 \quad 6.16000 \mathrm{E}-06 \quad 6.47600 \mathrm{E}-06 \quad 7.07900 \mathrm{E}-06 \quad 7.52400 \mathrm{E}-06$

$7.94300 \mathrm{E}-06 \quad 8.31500 \mathrm{E}-06 \quad 8.91300 \mathrm{E}-06 \quad 9.19000 \mathrm{E}-06 \quad 1.00000 \mathrm{E}-05$

$1.06800 \mathrm{E}-05 \quad 1.12200 \mathrm{E}-05 \quad 1.25900 \mathrm{E}-05 \quad 1.37100 \mathrm{E}-05 \quad 1.52300 \mathrm{E}-05$

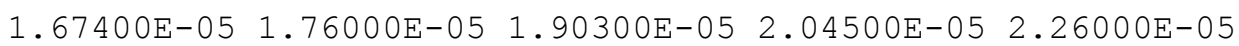

$2.49800 \mathrm{E}-05 \quad 2.79200 \mathrm{E}-05 \quad 2.92000 \mathrm{E}-05 \quad 3.05100 \mathrm{E}-05 \quad 3.38900 \mathrm{E}-05$

$3.72700 \mathrm{E}-05 \quad 3.98100 \mathrm{E}-05 \quad 4.55200 \mathrm{E}-05 \quad 4.78500 \mathrm{E}-05 \quad 5.01200 \mathrm{E}-05$

$5.55900 \mathrm{E}-05 \quad 6.14400 \mathrm{E}-05 \quad 6.31000 \mathrm{E}-05 \quad 6.79000 \mathrm{E}-05 \quad 7.07900 \mathrm{E}-05$

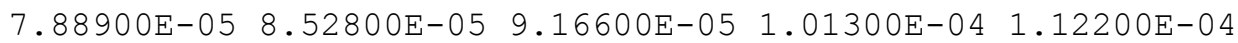

$1.30100 \mathrm{E}-04 \quad 1.36700 \mathrm{E}-05 \quad 1.58500 \mathrm{E}-04 \quad 1.67000 \mathrm{E}-04 \quad 1.77800 \mathrm{E}-04$

$2.04000 \mathrm{E}-04 \quad 2.14500 \mathrm{E}-04 \quad 2.43000 \mathrm{E}-04 \quad 2.75400 \mathrm{E}-04 \quad 3.04300 \mathrm{E}-04$

$3.53600 \mathrm{E}-04 \quad 3.98100 \mathrm{E}-04 \quad 4.54000 \mathrm{E}-04 \quad 5.14500 \mathrm{E}-04 \quad 5.83000 \mathrm{E}-04$

$6.31000 \mathrm{E}-04 \quad 6.77300 \mathrm{E}-04 \quad 7.07900 \mathrm{E}-04 \quad 7.48500 \mathrm{E}-04 \quad 8.48200 \mathrm{E}-04$

9.61100E-04 1.01000E-03 1.11700E-03 1.23400E-03 $1.36400 \mathrm{E}-03$

$\begin{array}{lllll}1.50700 \mathrm{E}-03 & 1.58500 \mathrm{E}-03 & 1.79600 \mathrm{E}-03 & 2.03500 \mathrm{E}-03 & 2.11300 \mathrm{E}-03\end{array}$

$\begin{array}{lllll}2.24900 \mathrm{E}-03 & 2.37100 \mathrm{E}-03 & 2.48500 \mathrm{E}-03 & 2.61300 \mathrm{E}-03 & 2.66100 \mathrm{E}-03\end{array}$

$\begin{array}{lllll}2.74700 \mathrm{E}-03 & 2.81800 \mathrm{E}-03 & 3.03500 \mathrm{E}-03 & 3.16200 \mathrm{E}-03 & 3.35500 \mathrm{E}-03\end{array}$

$3.54800 \mathrm{E}-03 \quad 3.70700 \mathrm{E}-03 \quad 3.98100 \mathrm{E}-03 \quad 4.30700 \mathrm{E}-03 \quad 4.64300 \mathrm{E}-03$

$5.00400 \mathrm{E}-03 \quad 5.53100 \mathrm{E}-03 \quad 6.26700 \mathrm{E}-03 \quad 7.10200 \mathrm{E}-03 \quad 7.46600 \mathrm{E}-03$

$8.25100 \mathrm{E}-03 \quad 9.11900 \mathrm{E}-03 \quad 1.00800 \mathrm{E}-02 \quad 1.11400 \mathrm{E}-02 \quad 1.17100 \mathrm{E}-02$

$1.27300 \mathrm{E}-02 \quad 1.38300 \mathrm{E}-02 \quad 1.50300 \mathrm{E}-02 \quad 1.58500 \mathrm{E}-02 \quad 1.66200 \mathrm{E}-02$

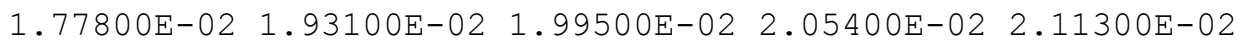

$\begin{array}{lllll}2.18700 \mathrm{E}-02 & 2.23900 \mathrm{E}-02 & 2.30400 \mathrm{E}-02 & 2.35800 \mathrm{E}-02 & 2.41800 \mathrm{E}-02\end{array}$

$2.44100 \mathrm{E}-02 \quad 2.47900 \mathrm{E}-02 \quad 2.51200 \mathrm{E}-02 \quad 2.58500 \mathrm{E}-02 \quad 2.60600 \mathrm{E}-02$

$\begin{array}{lllll}2.66100 \mathrm{E}-02 & 2.70000 \mathrm{E}-02 & 2.73800 \mathrm{E}-02 & 2.81800 \mathrm{E}-02 & 2.85000 \mathrm{E}-02\end{array}$

$2.90100 \mathrm{E}-02 \quad 2.98500 \mathrm{E}-02 \quad 3.07300 \mathrm{E}-02 \quad 3.16200 \mathrm{E}-02 \quad 3.18300 \mathrm{E}-02$

$3.43100 \mathrm{E}-02 \quad 3.69800 \mathrm{E}-02 \quad 4.08700 \mathrm{E}-02 \quad 4.35900 \mathrm{E}-02 \quad 4.63100 \mathrm{E}-02$

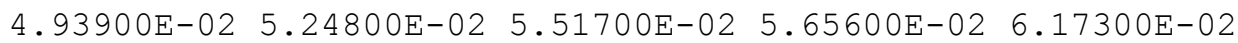

$6.73800 \mathrm{E}-02 \quad 7.20000 \mathrm{E}-02 \quad 7.49900 \mathrm{E}-02 \quad 7.95000 \mathrm{E}-02 \quad 8.23000 \mathrm{E}-02$

8.25000E-02 8.65200E-02 9.80400E-02 1.11100E-01 1.16800E-01

$\begin{array}{lllll}1.22800 \mathrm{E}-01 & 1.29100 \mathrm{E}-01 & 1.35700 \mathrm{E}-01 & 1.42600 \mathrm{E}-01 & 1.50000 \mathrm{E}-01\end{array}$

$1.57600 \mathrm{E}-01 \quad 1.65700 \mathrm{E}-01 \quad 1.74200 \mathrm{E}-01 \quad 1.83200 \mathrm{E}-01 \quad 1.92500 \mathrm{E}-01$

$\begin{array}{llllll}2.02400 \mathrm{E}-01 & 2.12800 \mathrm{E}-01 & 2.23700 \mathrm{E}-01 & 2.35200 \mathrm{E}-01 & 2.47200 \mathrm{E}-01\end{array}$

$\begin{array}{llllll}2.73200 \mathrm{E}-01 & 2.87300 \mathrm{E}-01 & 2.94500 \mathrm{E}-01 & 2.97200 \mathrm{E}-01 & 2.98500 \mathrm{E}-01\end{array}$

$3.02000 \mathrm{E}-01 \quad 3.33700 \mathrm{E}-01 \quad 3.68800 \mathrm{E}-01 \quad 3.87700 \mathrm{E}-01 \quad 4.07600 \mathrm{E}-01$

$\begin{array}{lllll}4.50500 \mathrm{E}-01 & 5.23400 \mathrm{E}-01 & 5.50200 \mathrm{E}-01 & 5.78400 \mathrm{E}-01 & 6.08100 \mathrm{E}-01\end{array}$

$6.39300 \mathrm{E}-01 \quad 6.72100 \mathrm{E}-01 \quad 7.06500 \mathrm{E}-01 \quad 7.42700 \mathrm{E}-01 \quad 7.80800 \mathrm{E}-01$

8.20900E-01 8.62900E-01 9.07200E-01 9.61600E-01 1.00300E+00

...

c continued on next page EAF 315 group structure 


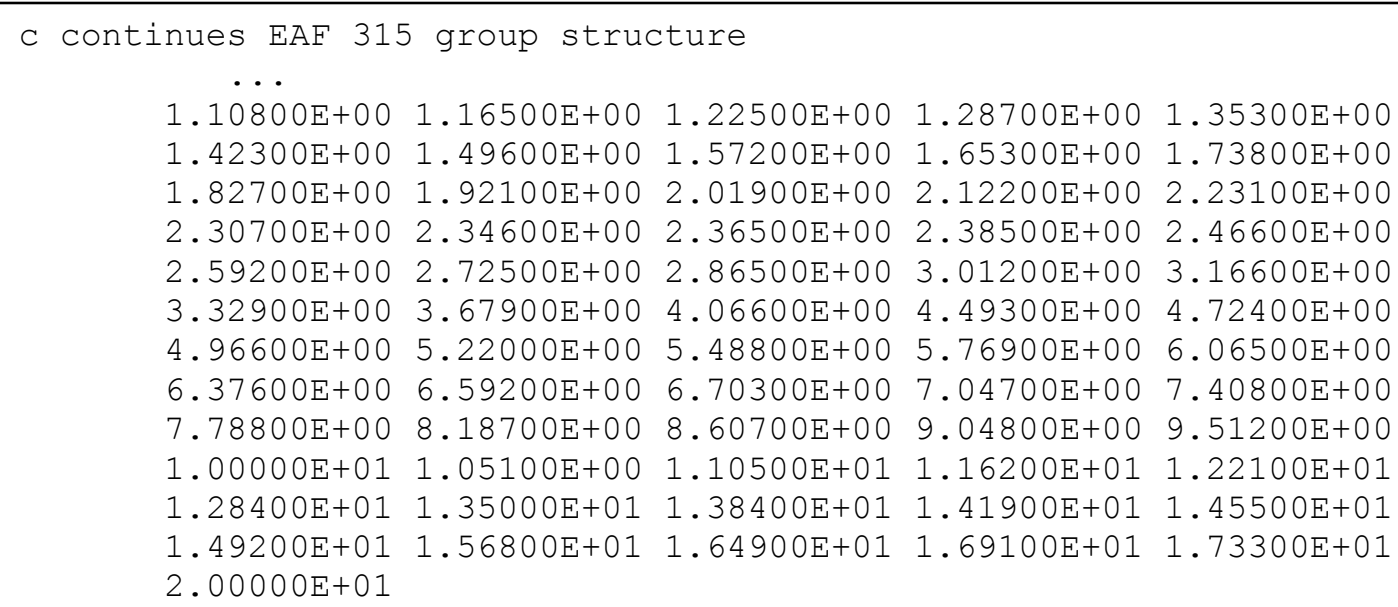


$\mathrm{C}$

C EAF activation cross sections provided in 351 group neutron c energy group structure from TRIPOLI+

e4 $\quad 1.10000 \mathrm{e}-10 \quad 3.00000 \mathrm{e}-09 \quad 5.50000 \mathrm{e}-09 \quad 1.00000 \mathrm{e}-08 \quad 1.50000 \mathrm{e}-08$

$2.00000 e-08 \quad 3.00000 e-08 \quad 3.20000 e-08 \quad 3.23800 e-08 \quad 4.30000 e-08$

$5.90000 e-08 \quad 7.70000 e-08 \quad 9.50000 e-08 \quad 1.00000 e-07 \quad 1.15000 e-07$

$1.34000 e-07 \quad 1.60000 e-07 \quad 1.89000 e-07 \quad 2.20000 e-07 \quad 2.48000 e-07$

$2.82500 e-07 \quad 3.14500 e-07 \quad 3.52000 e-07 \quad 3.91000 e-07 \quad 4.14000 e-07$

$4.33000 e-07 \quad 4.85000 e-07 \quad 5.31600 e-07 \quad 5.40000 e-07 \quad 6.25000 e-07$

$6.82600 \mathrm{e}-07 \quad 7.05000 \mathrm{e}-07 \quad 7.90000 \mathrm{e}-07 \quad 8.60000 \mathrm{e}-07 \quad 8.76400 \mathrm{e}-07$

$9.30000 e-07 \quad 9.86000 e-07 \quad 1.01000 e-06 \quad 1.03500 e-06 \quad 1.07000 e-06$

$1.08000 \mathrm{e}-06 \quad 1.09000 \mathrm{e}-06 \quad 1.11000 \mathrm{e}-06 \quad 1.12500 \mathrm{e}-06 \quad 1.17000 \mathrm{e}-06$

$1.23500 \mathrm{e}-061.30500 \mathrm{e}-06 \quad 1.37000 \mathrm{e}-06 \quad 1.44000 \mathrm{e}-06 \quad 1.44500 \mathrm{e}-06$

$1.51000 \mathrm{e}-061.59000 \mathrm{e}-06 \quad 1.67000 \mathrm{e}-06 \quad 1.75500 \mathrm{e}-06 \quad 1.84000 \mathrm{e}-06$

$1.85500 e-06 \quad 1.93000 e-06 \quad 2.02000 e-06 \quad 2.13000 e-06 \quad 2.36000 e-06$

$2.37200 e-06 \quad 2.76800 e-06 \quad 3.05900 e-06 \quad 3.38100 e-06 \quad 3.92800 e-06$

$4.12900 \mathrm{e}-06 \quad 4.47000 \mathrm{e}-06 \quad 4.67000 \mathrm{e}-06 \quad 5.04300 \mathrm{e}-06 \quad 5.62300 \mathrm{e}-06$

$6.16000 e-06 \quad 6.47600 e-06 \quad 7.07900 e-06 \quad 7.52400 e-06 \quad 7.94300 e-06$

$8.31500 e-06 \quad 8.91300 e-06 \quad 9.19000 e-06 \quad 1.00000 e-05 \quad 1.06800 e-05$

$1.12200 e-05 \quad 1.25900 e-05 \quad 1.37100 e-05 \quad 1.52300 e-05 \quad 1.67400 e-05$

$1.76000 e-05 \quad 1.90300 e-05 \quad 2.04500 e-05 \quad 2.26000 e-05 \quad 2.49800 e-05$

$2.79200 e-05 \quad 2.92000 e-05 \quad 3.05100 e-05 \quad 3.38900 e-05 \quad 3.72700 e-05$

$3.98100 e-05 \quad 4.55200 e-05 \quad 4.78500 e-05 \quad 5.01200 e-05 \quad 5.55900 e-05$

$6.14400 e-05 \quad 6.31000 e-05 \quad 6.79000 e-05 \quad 7.07900 e-05 \quad 7.88900 e-05$

$8.52800 e-05 \quad 9.16600 e-05 \quad 1.01300 e-04 \quad 1.12200 e-04 \quad 1.30100 e-04$

$1.36700 e-04 \quad 1.58500 e-04 \quad 1.67000 e-04 \quad 1.77800 e-04 \quad 2.04000 e-04$

$2.14500 e-04 \quad 2.43000 e-04 \quad 2.75400 e-04 \quad 3.04300 e-04 \quad 3.53600 e-04$

$3.98100 e-04 \quad 4.54000 e-04 \quad 5.14500 e-04 \quad 5.83000 e-04 \quad 6.31000 e-04$

$6.77300 \mathrm{e}-04 \quad 7.07900 \mathrm{e}-04 \quad 7.48500 \mathrm{e}-04 \quad 8.48200 \mathrm{e}-04 \quad 9.61100 \mathrm{e}-04$

$1.01000 e-031.11700 e-03 \quad 1.23400 e-03 \quad 1.36400 e-03 \quad 1.50700 e-03$

$1.58500 e-03 \quad 1.79600 e-03 \quad 2.03500 e-03 \quad 2.11300 e-03 \quad 2.24900 e-03$

$\begin{array}{lllll}2.37100 e-03 & 2.48500 e-03 & 2.61300 e-03 & 2.66100 e-03 & 2.74700 e-03\end{array}$

$2.81800 e-03 \quad 3.03500 e-03 \quad 3.16200 e-03 \quad 3.35500 e-03 \quad 3.54800 e-03$

$3.70700 e-03 \quad 3.98100 e-03 \quad 4.30700 e-03 \quad 4.64300 e-03 \quad 5.00400 e-03$

$5.53100 e-03 \quad 6.26700 e-03 \quad 7.10200 e-03 \quad 7.46600 e-03 \quad 8.25100 e-03$

$9.11900 \mathrm{e}-031.00800 \mathrm{e}-02 \quad 1.11400 \mathrm{e}-02 \quad 1.17100 \mathrm{e}-02 \quad 1.27300 \mathrm{e}-02$

$1.38300 \mathrm{e}-021.50300 \mathrm{e}-021.58500 \mathrm{e}-02 \quad 1.66200 \mathrm{e}-021.77800 \mathrm{e}-02$

$1.93100 e-02 \quad 1.99500 e-02 \quad 2.05400 e-02 \quad 2.11300 e-02 \quad 2.18700 e-02$

$2.23900 e-02 \quad 2.30400 e-02 \quad 2.35800 e-02 \quad 2.41800 e-02 \quad 2.44100 e-02$

$2.47900 e-02 \quad 2.51200 e-02 \quad 2.58500 e-02 \quad 2.60600 e-02 \quad 2.66100 e-02$

$2.70000 e-02 \quad 2.73800 e-02 \quad 2.81800 e-02 \quad 2.85000 e-02 \quad 2.90100 e-02$

$2.98500 e-02 \quad 3.07300 e-02 \quad 3.16200 e-02 \quad 3.18300 e-02 \quad 3.43100 e-02$

$3.69800 e-02 \quad 4.08700 e-02 \quad 4.35900 e-02 \quad 4.63100 e-02 \quad 4.93900 e-02$

$5.24800 e-02 \quad 5.51700 e-02 \quad 5.65600 e-02 \quad 6.17300 e-02 \quad 6.73800 e-02$

$7.20000 e-027.49900 e-02 \quad 7.95000 e-02 \quad 8.23000 e-02 \quad 8.25000 e-02$

$8.65200 e-029.80400 e-02 \quad 1.11100 e-01 \quad 1.16800 e-01 \quad 1.22800 e-01$

$1.29100 \mathrm{e}-011.35700 \mathrm{e}-01 \quad 1.42600 \mathrm{e}-01 \quad 1.50000 \mathrm{e}-01 \quad 1.57600 \mathrm{e}-01$

$1.65700 \mathrm{e}-011.74200 \mathrm{e}-01 \quad 1.83200 \mathrm{e}-01 \quad 1.92500 \mathrm{e}-012.02400 \mathrm{e}-01$

$\begin{array}{llllll}2.12800 e-01 & 2.23700 e-01 & 2.35200 e-01 & 2.47200 e-01 & 2.73200 e-01\end{array}$

$2.87300 e-012.94500 e-01 \quad 2.97200 e-01 \quad 2.98500 e-01 \quad 3.02000 e-01$

$3.33700 e-013.68800 e-01 \quad 3.87700 e-01 \quad 4.07600 e-01 \quad 4.50500 e-01$

$\cdots$

c continued next page TRIPOLIS+ group structure 


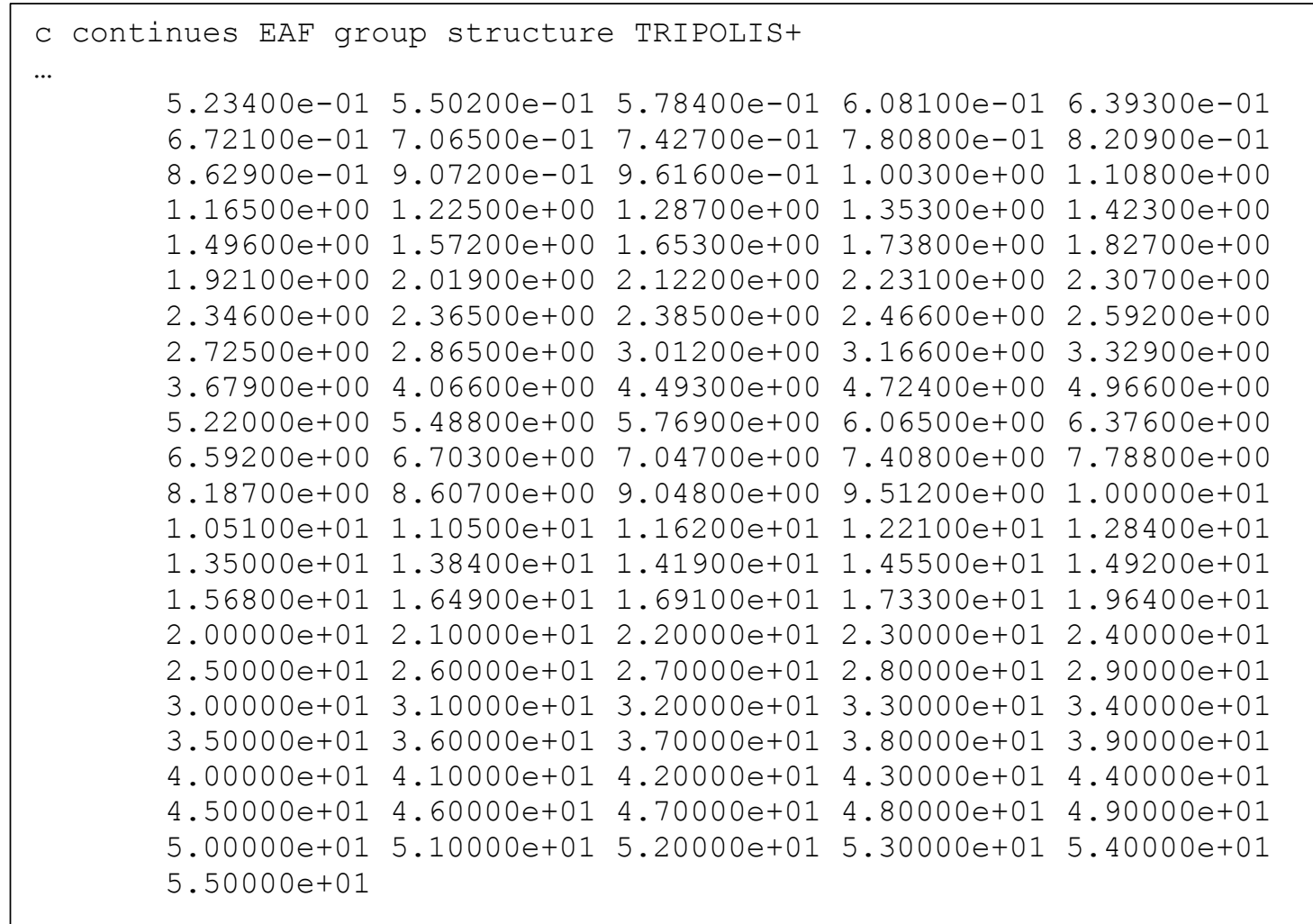

